\title{
Characteristics that influence purchase choice for cannabis products: a systematic review
}

Jennifer Donnan ${ }^{1 *} \mathbb{0}$, Omar Shogan ${ }^{1}$, Lisa Bishop ${ }^{1,2}$, Michelle Swab² and Maisam Najafizada² $^{2}$

\begin{abstract}
Introduction: When non-medical cannabis use became legal, government regulators implemented policies to encourage safer consumption through access to a regulated market. While this market is growing, sales still occur through unregulated channels. This systematic review identifies factors influencing cannabis purchasing to help policymakers understand why consumers still purchase illicit market cannabis (registered with PROSPERO CRD42020176079).
\end{abstract}

Methods: A comprehensive search strategy included databases in health, business, and social science fields (inception to June 2020). Studies were eligible for inclusion if they were conducted with persons who purchase cannabis and examine at least one attribute that would influence purchase choice and were published in the English language. Studies could be of any methodological design. Two independent reviewers completed two levels of screening, and all extraction was verified by a second reviewer. A qualitative synthesis of the findings was completed. The quality of the included studies was assessed using the Mixed Methods Appraisal Tool.

Results: Of the 4839 citations screened, 96 were eligible for full-text review and 35 were included in the final synthesis. Aspects of price were the most common factors (27 studies). Twenty studies measured price elasticity; most studies found that demand was price inelastic. Many other attributes were identified (e.g., product quality, route of administration, product recommendations, packaging), but none were explored in depth. Eleven studies addressed aspects of product quality including demand elasticity based on quality, potency, and aroma. Studies also explored consumer-perceived "quality" but provided no definition; differences in quality appeared to impact consumer choice. Smoking cannabis appeared to be the preferred route of administration but was only examined in three studies. There was insufficient data to understand in the impact of other attributes on choice. There appeared to be preference heterogeneity for different attributes based on the consumer's experience, reason for use, and gender.

Conclusion: While price influences choices, demand is relatively inelastic. This suggests that consumers may be seeking lowest-cost, unregulated cannabis to avoid reducing consumption. Beyond price, there is a significant gap in our understanding of consumer choices. Perceived quality does appear to impact choice; however, more research is needed due to the lack of a recognized definition for cannabis quality.

Keywords: Cannabis, Public health, Cannabis policy, Choice attributes, Purchase decisions, Price elasticity

*Correspondence: Jennifer.donnan@mun.ca

${ }^{1}$ School of Pharmacy, Memorial University of Newfoundland and Labrador, St. John's, Canada

Full list of author information is available at the end of the article

\section{Introduction}

Cannabis is the second most commonly used psychoactive substance world-wide (Peacock et al., 2018; United Nations Office on Drugs and Crime, 2019). The global 
estimated annual prevalence of cannabis consumers aged $15-64$ was $3.8 \%$ in 2017 or approximately 188 million people (Peacock et al., 2018). The number of people who use cannabis annually is also estimated to have increased by roughly 30\% between 1998 and 2017 (United Nations Office on Drugs and Crime, 2019).

This rise may be accredited to recent changes in cultural-norms and policies in several countries regarding cannabis use (Bahji and Stephenson, 2019; National Academies of Sciences et al., 2017; National Institute of Health, 2015). Currently, cannabis for non-medicinal use is legal in Canada, Georgia, South Africa, Uruguay, the Australian Capital Territory in Australia, and specific regions in the USA (ACT Government, 2020; BBC News, 2018; Guthrie, 2018; United Nations Office on Drugs and Crime, 2019). Within the USA, there are 19 states and the federal District of Columbia which have legalized recreational cannabis (Solutions, 2019). Several countries have also adopted milder forms of punishment in regulating cannabis without actual legalization, through decriminalization or unenforced laws (Areesantichai et al., 2020; Hanford, n.d.; Smith, 2020). Moreover, medicinal use of cannabis has been prevalent and legalized in many countries for some time.

Illegal cannabis sales are still largely prevalent in Canada and beyond, with only $48 \%$ of Canadian cannabis consumers making their last purchase from a legal source and illegal retailers in California outnumbering legal retailers three to one (Wadsworth et al., 2021). People who use cannabis attribute the persistence of the illegal market to numerous issues that may decrease the appeal of legal cannabis. According to the media, cannabis consumers reported issues such as high cost (Deschamps, 2020; Esfandiari, 2019; Fahmy, 2019; Johnson, Glen et al., 2019; McCabe, 2019; Shackford, 2019; The Canadian Press, 2020; Tunney, 2019a), poor cannabis quality (Ahearn, 2018; Turvill, 2020), product moisture (Israel, 2019; Turvill, 2020), limited supply (CBC News, 2019; Cecco, 2019; Esfandiari, 2019; Geraghty, 2019; Johnson, Glen et al., 2019; Mazur, 2019; Tunney, 2019a; Williams, 2019), distance to licensed stores (Esfandiari, 2019; Johnson, Glen et al., 2019; Tunney, 2019b), and inconvenient packaging (Lamers, 2019). Through crowdsourced cannabis prices, Statistics Canada confirmed that the price of legal cannabis is more expensive compared to illegal cannabis (Statistics Canada, 2020). From 2018 to 2019, the average price of legal cannabis in Canada increased from $\$ 9.69$ per gram to $\$ 10.30$, while the average price of illegal cannabis dropped from $\$ 6.44$ per gram to $\$ 5.73$ (Statistics Canada, 2020). This mirrors the experience in the USA where illegal cannabis prices dropped substantially in states where it became legalized (Smart et al., 2017).
The multi-attribute utility theory (Torrance et al., 1982) states that when individuals make decisions, their choices are based on their preferences towards certain attributes of that choice. Likewise, there are many attributes or factors that people consider when making the choice between legal or illegal cannabis. A better understanding of the degree to which these specific factors influence decisions can help inform cannabis policy. Research to date has predominantly examined the effect of cannabis price on consumer demand by measuring price elasticity of demand. Price elasticity of demand (Gilroy et al., 2020) represents the degree to which demand for cannabis changes as price fluctuates. A common method to examine price elasticity has been the marijuana-purchase task (MPT) (Aston and Meshesha, 2020). The MPT is a simulated purchase scenario which evaluates consumers' demand for cannabis in relation to a change in price (e.g., from free to $\$ 10$ over 20 increments). This method is also used to look at demand elasticity in relation to characteristics other than price, such as product quality.

There are considerations or attributes beyond price that are important to consumers when they purchase cannabis. Some research has been done to focus on factors like quality, aroma, potency, packaging, and warning labels. However, because cannabis legalization is a new in many countries, there is a lack of research that attempts to bring existing research evidence on cannabis choice behavior together. Understanding the role that all of attributes of choice play in decision making may be informative for refining cannabis policies to better support public health and safety as well as meet consumer needs. This can also offer insight for countries looking to legalize cannabis for either medicinal or non-medicinal use. The purpose of this systematic review is to identify what factors influence cannabis purchasing behavior to inform the design of a cannabis choice modeling study. The secondary objective was to identify gaps and limitations in the existing evidence base.

\section{Methods and analysis Study design}

This study was designed in accordance with the PRISMA statement on systematic reviews (Moher et al., 2009) and is registered (CRD42020176079) with PROSPERO (International Prospective Register of Systematic Reviews). The Covidence online systematic review software was used to assist in screening, selection, and data extraction.

\section{Eligibility criteria}

The research team used the SPIDER search strategy tool (Cooke et al., 2012) to define the key elements of the review question. This tool is designed specifically for research questions that lend themselves better to 
qualitative or mixed methods approaches. The inclusion and exclusion criteria along with the SPIDER search protocol are described in Table 1.

\section{Data sources and search strategy}

A comprehensive search strategy which aimed to find both published and unpublished studies was developed in conjunction with an experienced librarian (MS) and peer reviewed by a second librarian. The search included databases in health (Medline, EMBASE, PsycINFO), business (ABI/INFORM, Business Source Complete), and social science (ASSIA, IBSS, SocINDEX, Sociological Abstracts) fields. A broad index search in Scopus was also performed. The complete search strategy is included in the appendix. The strategy was first created in Ovid MEDLINE and was modified to fit other databases' search criteria. Reference lists of key articles were also screened (JD). The search was conducted from inception to June 2020 to each database.

\section{Screening and selection process}

Two reviewers (JD, OS) independently screened articles in Covidence utilizing a two-stage screening process based on the eligibility criteria. In the first stage, articles were screened based on the title and abstract. Articles which did not meet the inclusion criteria were excluded. Disagreements were subsequently resolved via discussion until consensus was achieved. In the second stage, full-text screening of the included articles was independently performed by both reviewers to determine eligibility. Reasons for exclusion during this stage were documented. Disagreements were again resolved through discussion. A third reviewer (LB) was consulted in select cases when meeting the inclusion criteria was unclear.

\section{Data extraction}

Extracted information included study characteristics, participant characteristics, and attribute characteristics. Study characteristics included year of publication, methods used, country, time period of data collection, and sample size. Participant characteristics included gender/ sex and non-medicinal vs. medicinal vs. dual use (both non-medicinal and medicinal) use of cannabis. Attribute characteristics deemed to be relevant to consumer choice, as well as a narrative summary of these characteristics, were also extracted.

\section{Data synthesis}

Because these attributes were investigated using a diverse range of methodologies and recruited a variety of study populations, there was no attempt to combine studies statistically. Only qualitative synthesis was completed. Where possible, data exploring differences in preferences among sub-groups of the population or between the legal and illegal market were highlighted.

\section{Quality assessment}

The Mixed Methods Appraisal Tool (MMAT) (Hong et al., 2018) was used to assess the quality of each of the included studies. The MMAT tool provides five critical appraisal questions for each of the five possible study design categories. Only two categories were required for appraisal in this systematic review. These were "qualitative" and "quantitative descriptive." For qualitative studies, questions cover appropriate method, findings adequately derived from the data, interpretation substantiated by data, and coherence between qualitative sources. For quantitative descriptive studies, questions cover: the appropriateness of sampling, representativeness of sample, appropriate measure, overall risk of bias being low, and appropriateness of statistical analysis. Each question has three possible responses: yes, no, and cannot tell. Quality assessment was completed by two reviewers (JD, OS), and disagreements were resolved through discussion. Studies were not excluded based on not meeting a quality threshold, but rather quality assessment was considered in the interpretation of the findings.

\section{Results}

A total of 4839 titles and abstracts were screened after duplicates were removed. Ninety-six articles were eligible for full-text review; of these, 61 were excluded due to (1) no attributes of choice $(n=26),(2)$ not a research study $(n=15)$, (3) abstract only $(n=10)$, (4) duplicate study

Table 1 Study eligibility criteria

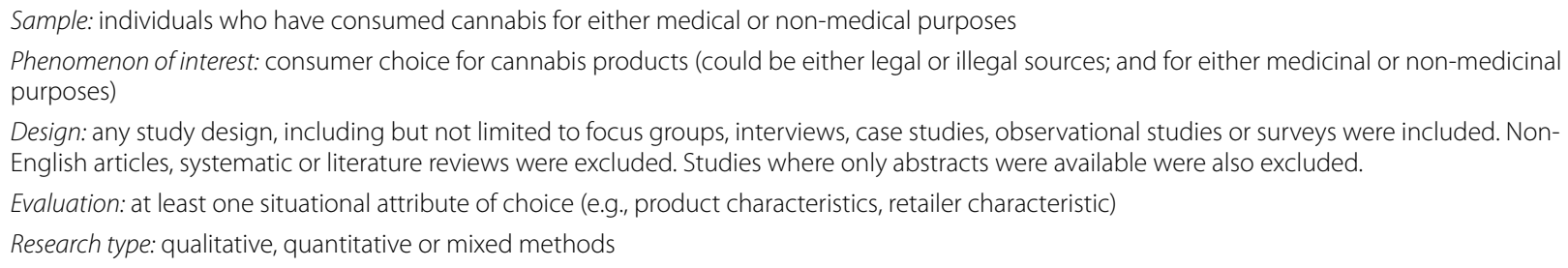


$(n=1),(5)$ duplication of data $(n=4),(6)$ unable to find text $(n=2)$, and other $(n=3)$. A total of 35 publications were included (Fig. 1, Table 2). Most were conducted within the USA $(n=25)$; five were carried out in Canada, six in other international locations, and one was of unknown location (three studies were conducted in more than one country). The most frequently examined attribute was price, with twenty-seven studies looking at some measure of the impact of price on choice. Most studies were conducted in a population where cannabis was not legalized for non-medical use $(n=19)$, some were conducted in legalized environments $(n=9)$, while other had unknown or mixed legalization status $(n=8)$. Only fourteen studies (Aston et al., 2019; Boehnke et al., 2019; Capler et al., 2017; Chait and Burke, 1994; Cole et al., 2008; Gilbert and DiVerdi, 2018; Goodman et al., 2019; Goudie et al., 2007; Halcoussis et al., 2017; Reinarman, 2009; Riley et al., 2020; Shi et al., 2019; Shukla, 2003; Wadsworth et al., 2019; Williams, 2004) explored nonprice attributes, further categorized into the following themes: quality, route of administration, packaging, and product recommendations (Fig. 2).

\section{Quality appraisal}

Generally, studies were of appropriate quality to address the relevant study question. The design elements that were most difficult to assess were "representativeness of the sample" and "low risk of non-response." Studies which collected data through crowdsourcing (e.g., Amazon Mechanical Turk) or participant self-identification, compared to administrative data or national surveys, are more likely to be subject to selection bias, non-response bias, and recall bias. In studies where sampling was appropriate and representative of the population, it is important to note that several studies had very narrow inclusion criteria, and therefore, the samples are only representative of that particular subset of the population. All but three studies used a quantitative methodology and were assessed using the "quantitative descriptive" set of questions. There was a wide range of methodologies

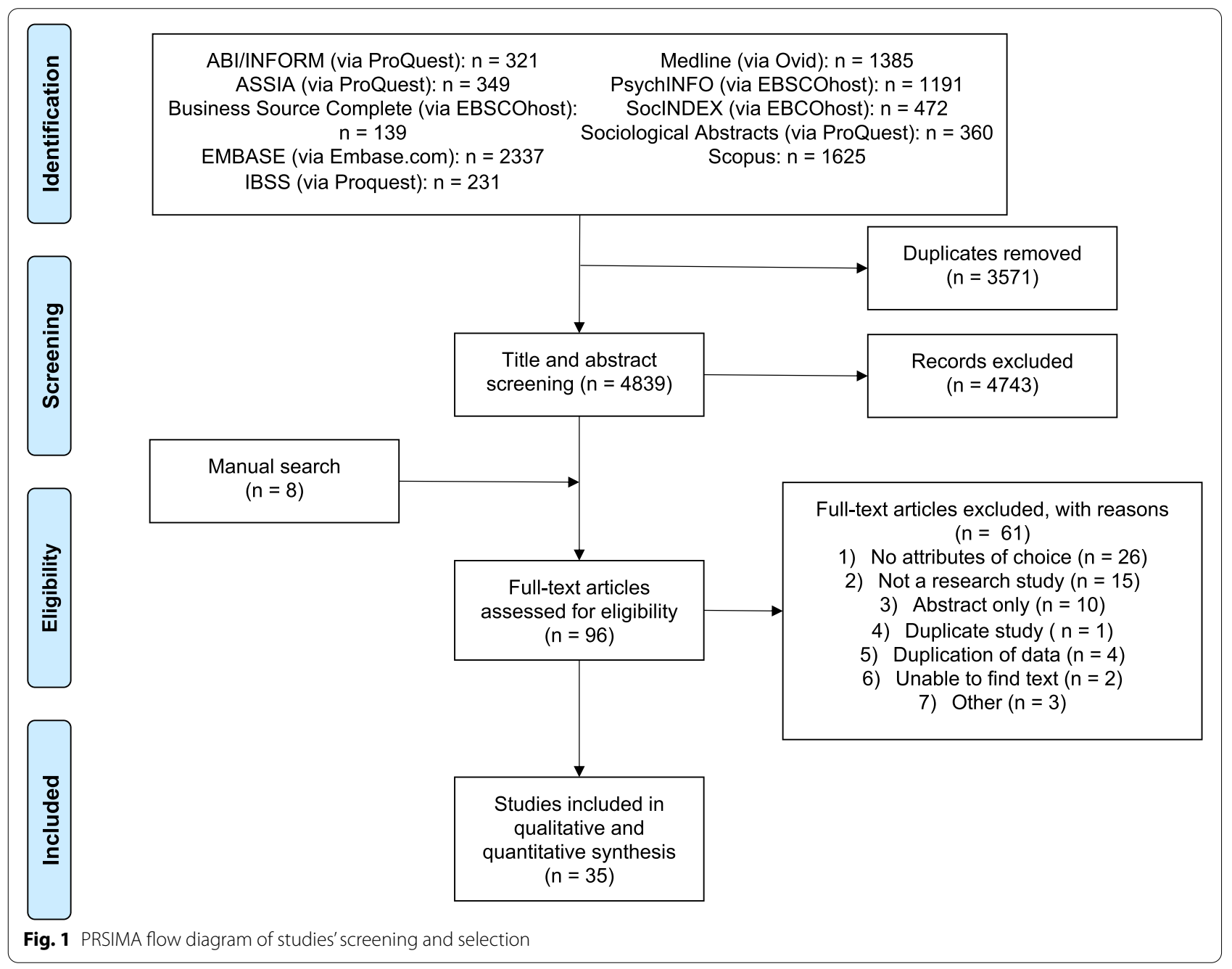


Donna et al. Journal of Cannabis Research

(2022) $4: 9$

Page 5 of 27

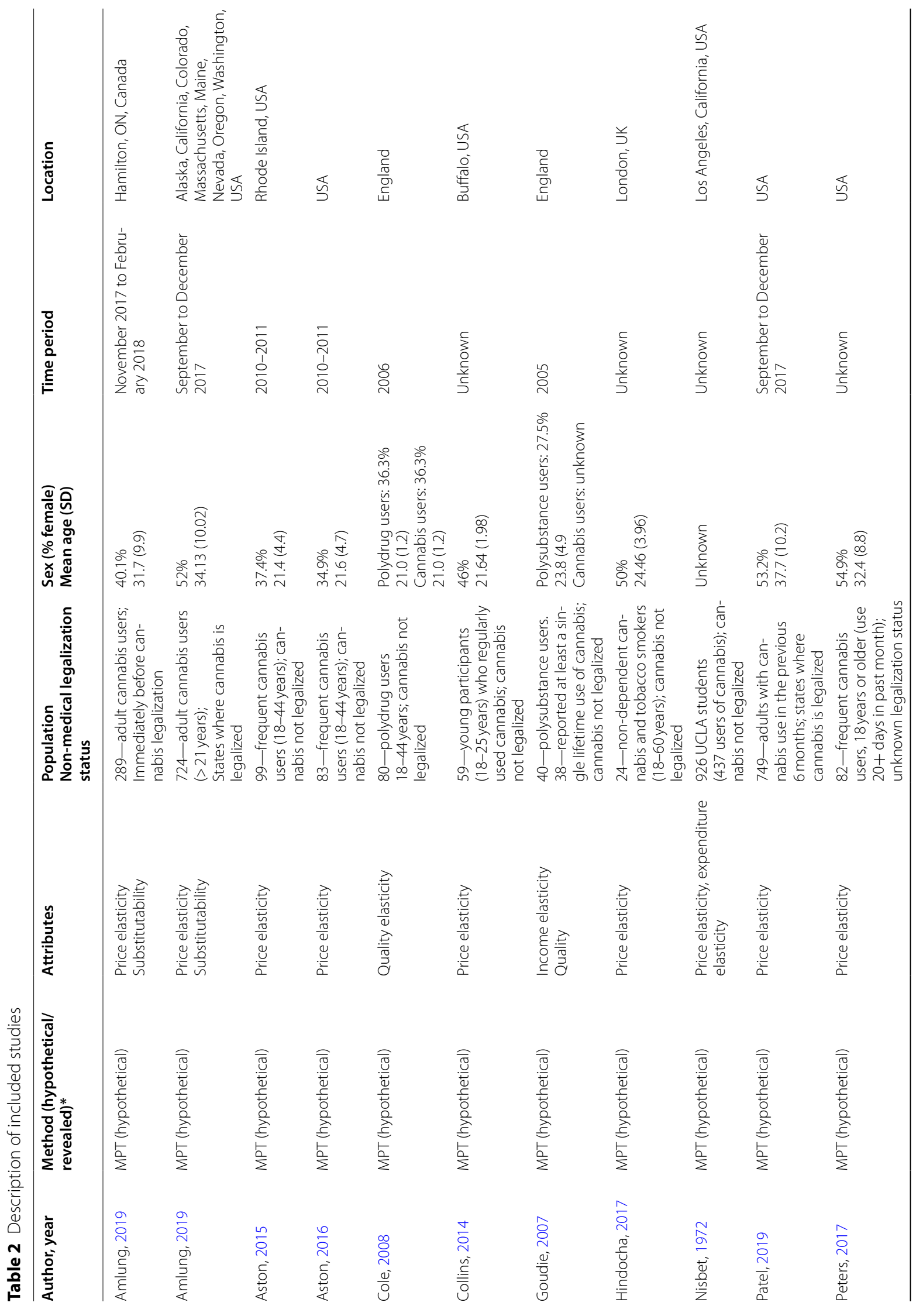




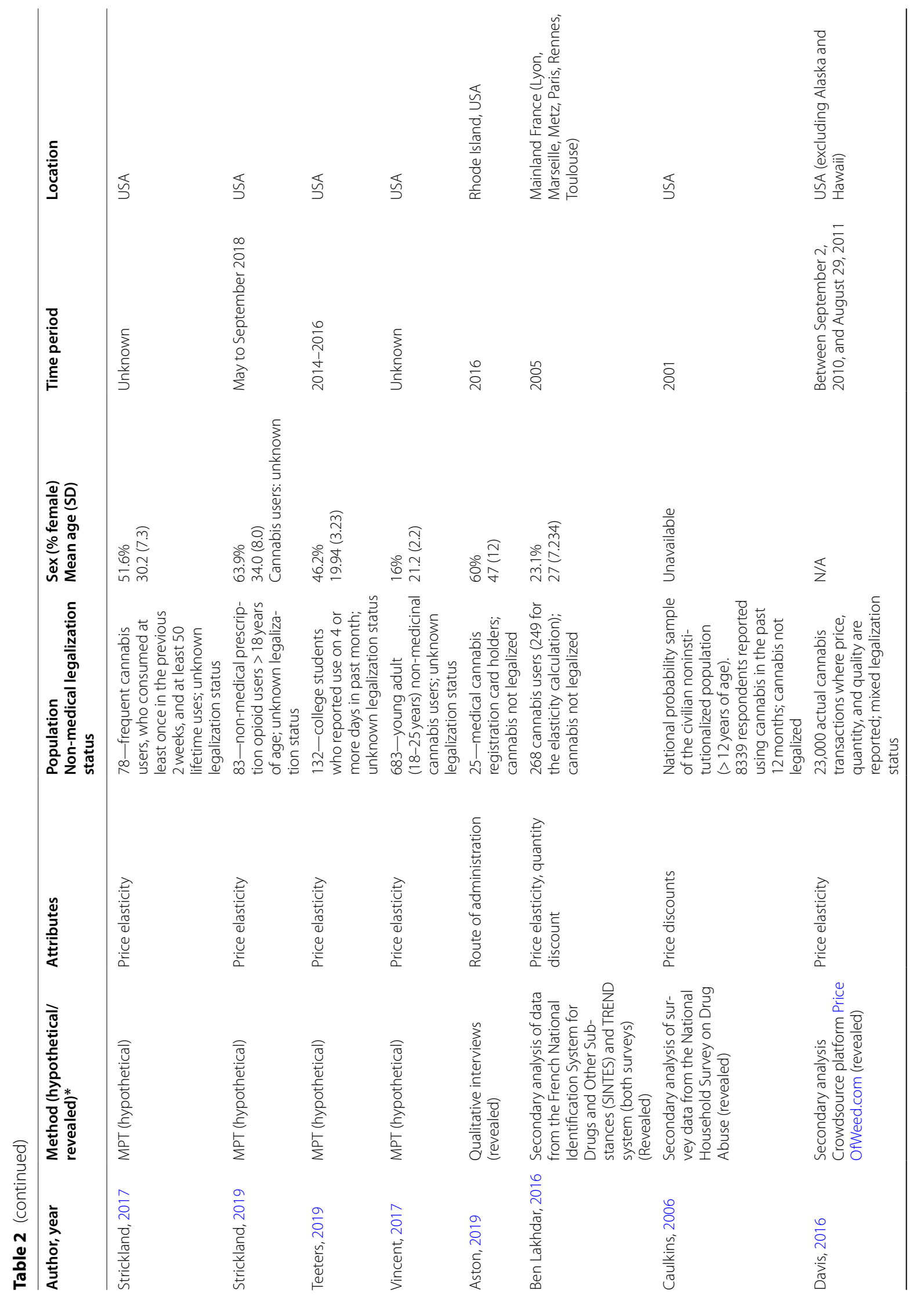




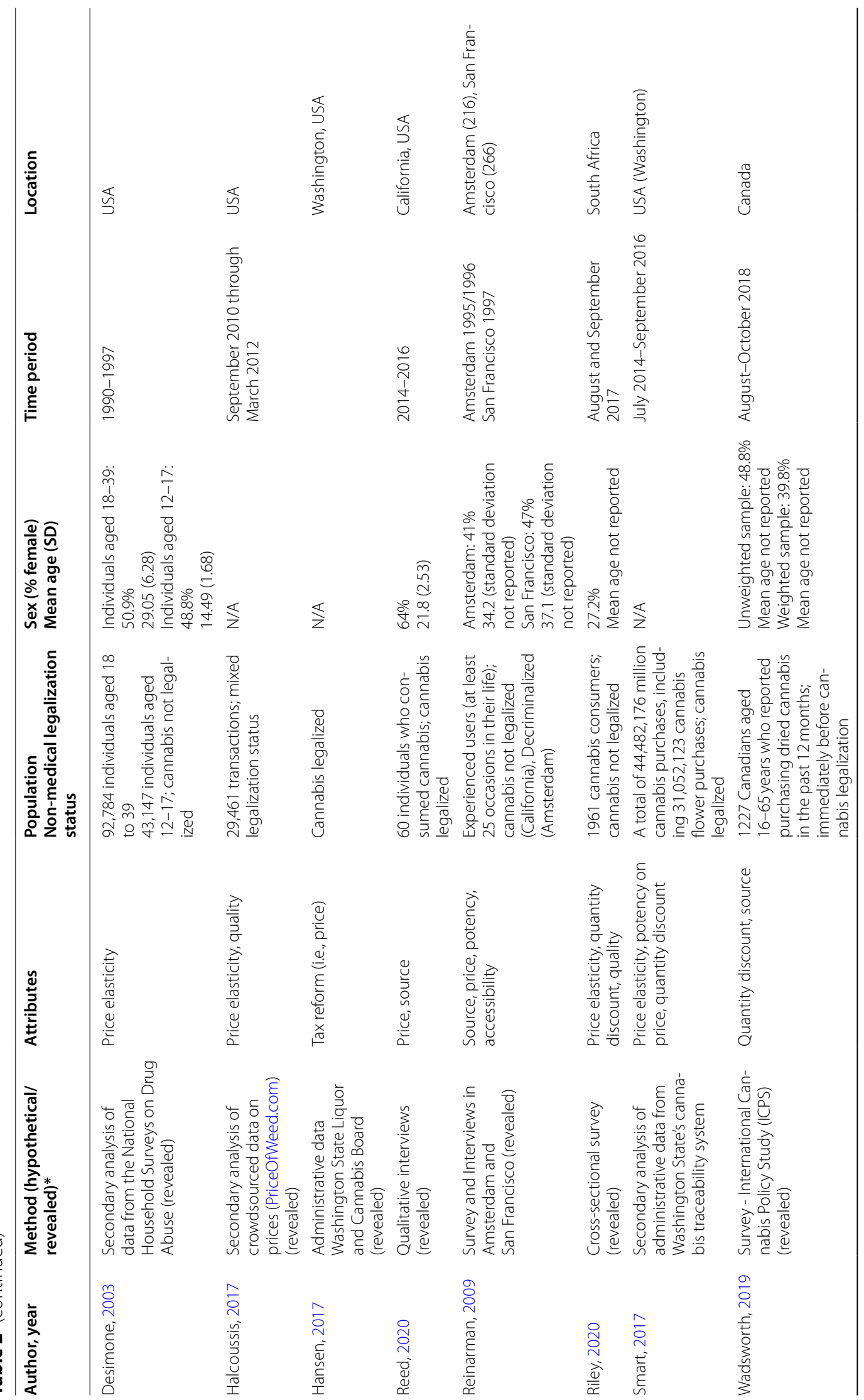




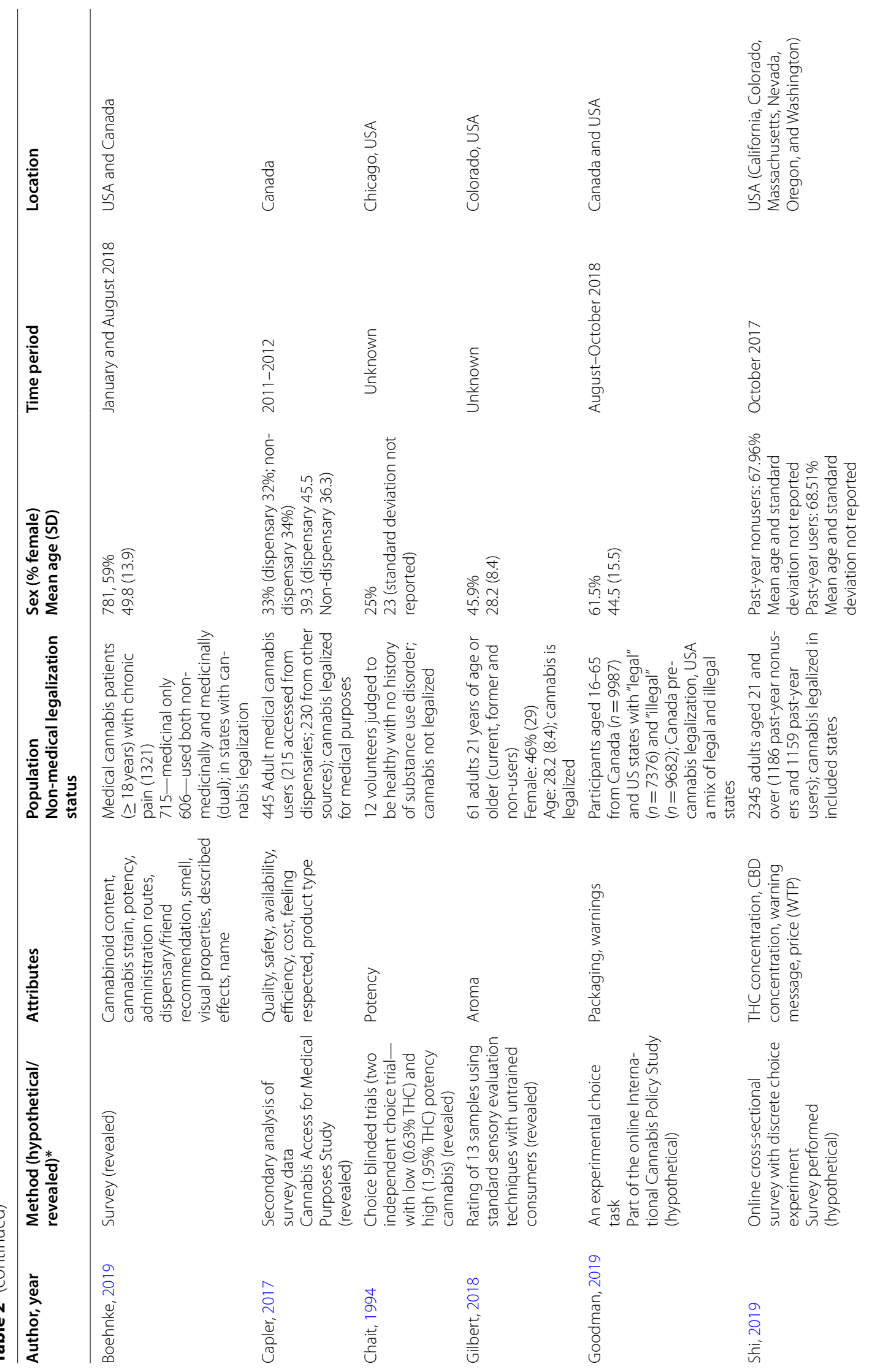




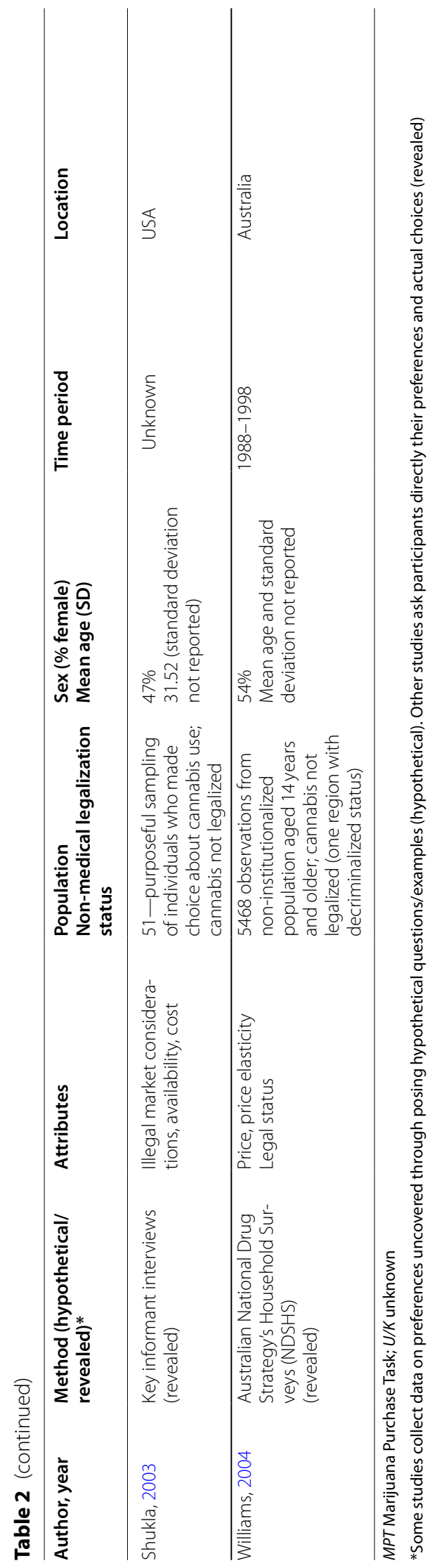




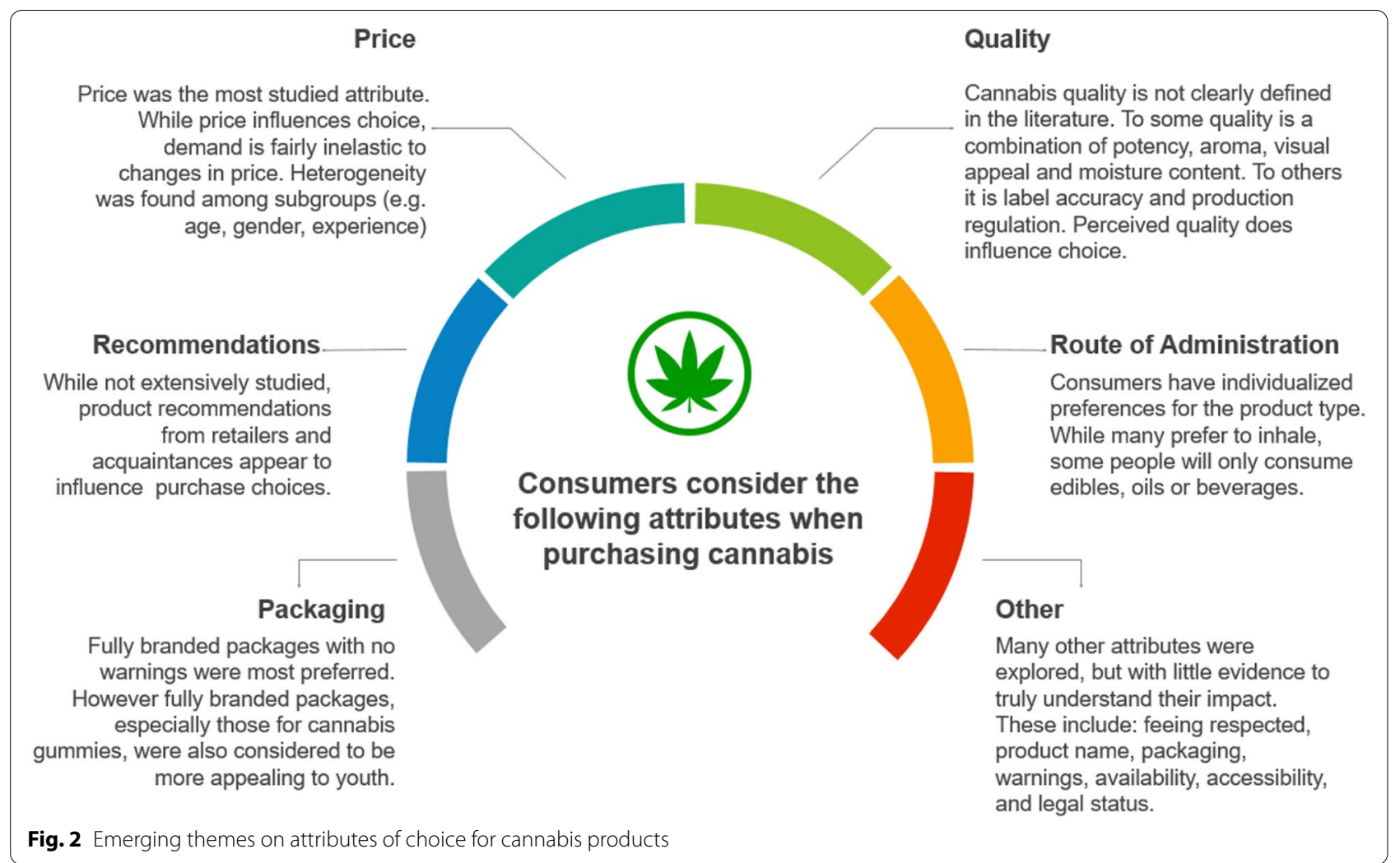

used, some with more complex analyses; however, measures and statistics were generally appropriate for the specific methods used. A complete table outlining the results of the quality appraisal can be found in the online appendix.

\section{Price-related factors}

Studies which examined price can be further divided into two categories: those that utilized a MPT design $(n=12)$ and those that did not $(n=15)$.

\section{Marijuana purchase task (MPT) studies}

Twelve studies used the MPT approach to examine purchase demand in relation to price, which allows for the estimation of several demand predictors (Table 3) (Gilroy et al., 2020). These include: price elasticity, which is the sensitivity of quantity purchased to increases in prices; $P_{\text {max }}$, which is the price at which demand become elastic; intensity $\left(Q_{0}\right)$, which is the amount consumed when price is free; $O_{\max }$, which is the maximum expenditure; and breakpoint, which is the cost at which consumption is suppressed to zero.

Elasticity $(\alpha)$, in the context of purchase task studies, refers to the rate that point elasticity changes as a function of price. Generally, elasticity values for included studies were small $(\alpha<0.01)$ (Amlung et al., 2019;
Amlung and MacKillop, 2019; Aston et al., 2015, 2016; Collins et al., 2014; Hindocha et al., 2017; Nisbet and Vakil, 1972; Patel and Amlung, 2019; Peters et al., 2017; Strickland et al., 2017, 2019; Teeters et al., 2019). Amlung and MacKillop (2019) and Amlung et al. (2019) compared elasticities of illegal and legal cannabis products. While both were inelastic, illegal cannabis was more elastic than legal. Collins et al. (2014) used a much wider price range than other studies with price per joint ranging from $\$ 0-\$ 160$. Therefore, they found the demand was elastic at the mean; however, demand was inelastic at the lower range (up to \$15) and changed to elastic at the higher ranges (over $\$ 15$ ).

Two studies examined to what extent legal and illegal cannabis were substitutes for one another (Amlung et al., 2019; Amlung and MacKillop, 2019). These studies found when legal cannabis was available, illegal cannabis became more elastic and demand more responsive to changes in price in the illegally sourced product. The presence of illegal cannabis did not have a significant impact of the demand elasticity of legal product. Substitutability was also demonstrated, as the maximum expenditure for illegal cannabis $\left(P_{\max }\right)$ was much lower in the presence of legal cannabis. However, the maximum expenditure on legal cannabis did not drop to the same extent in the presence of illegal cannabis. 


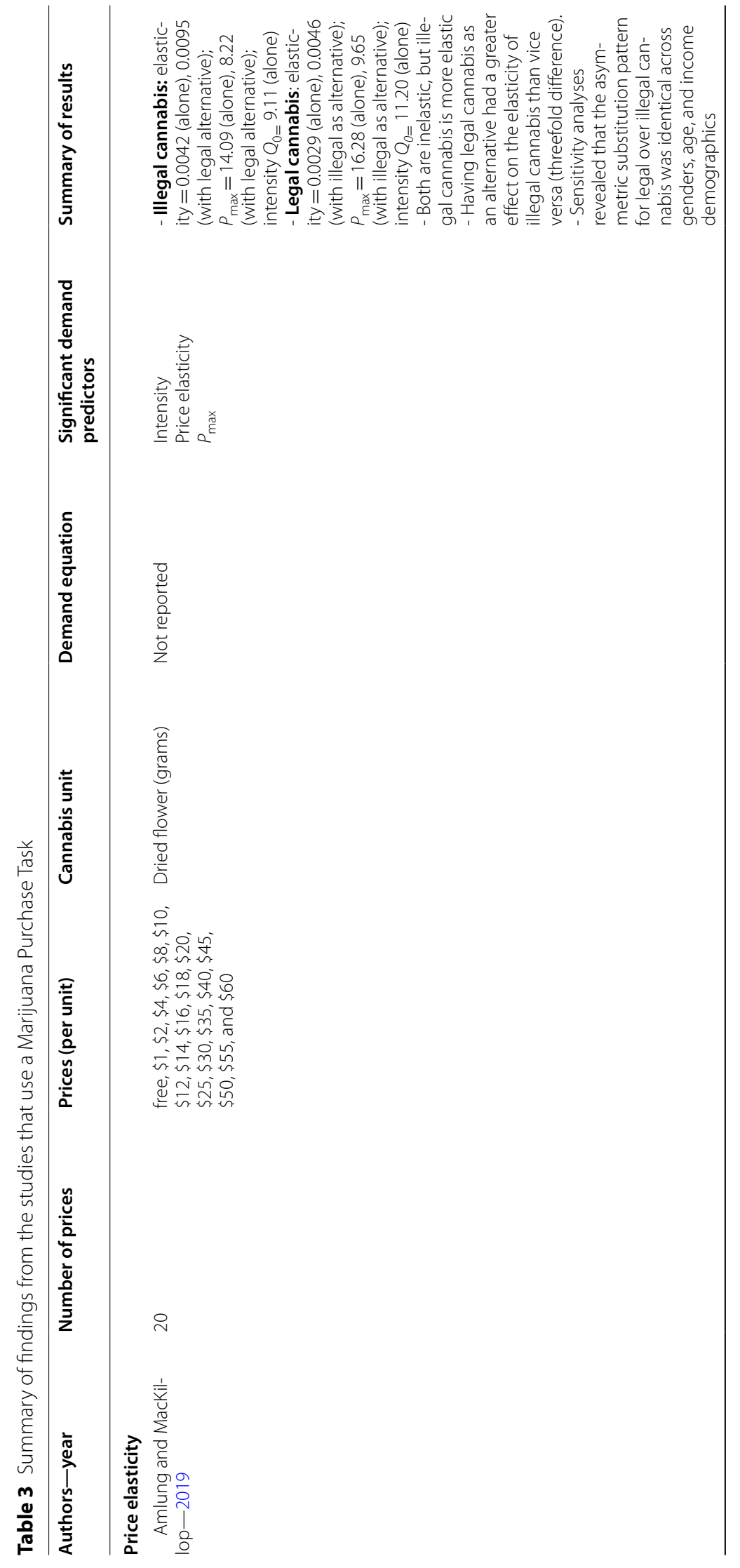




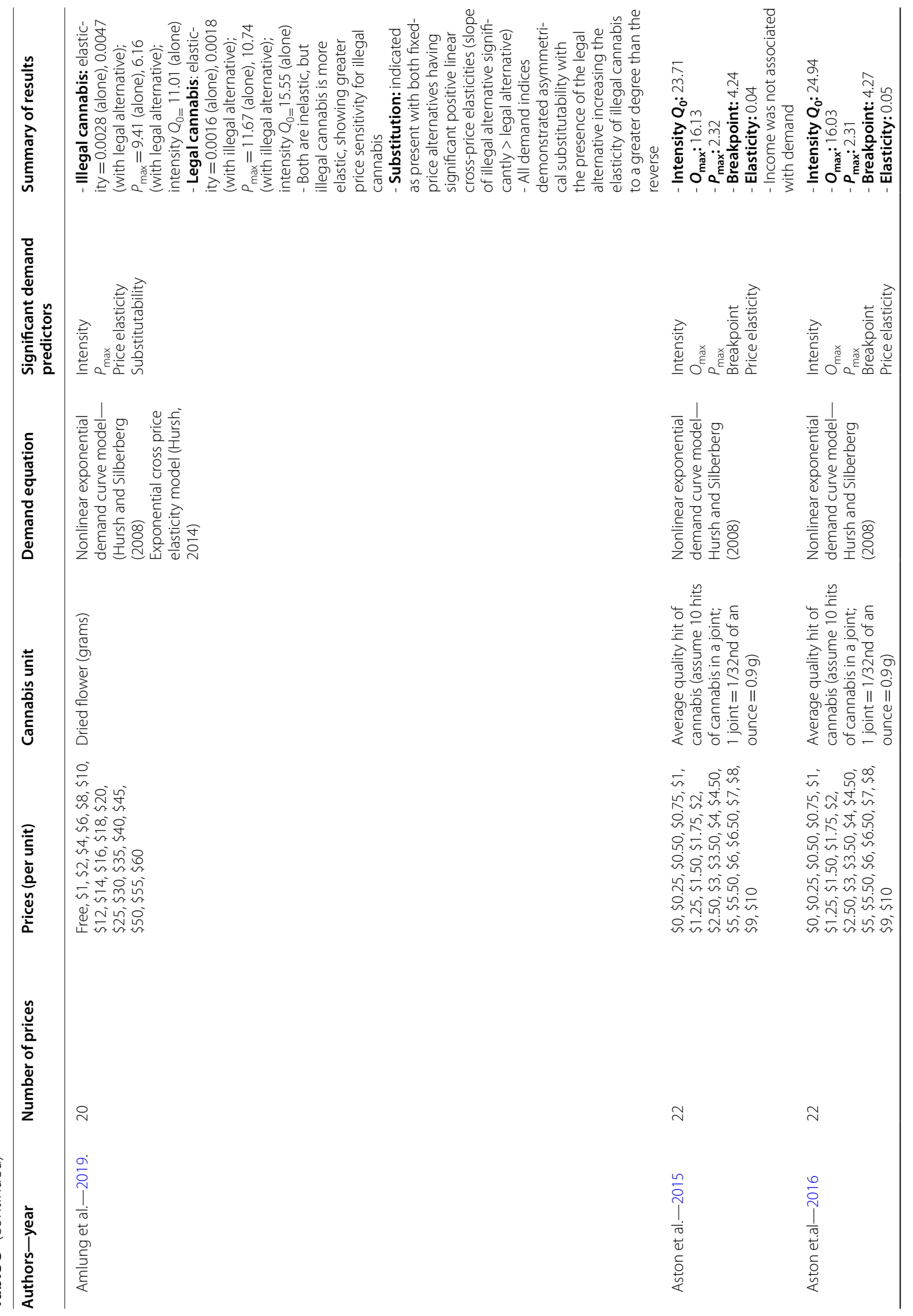




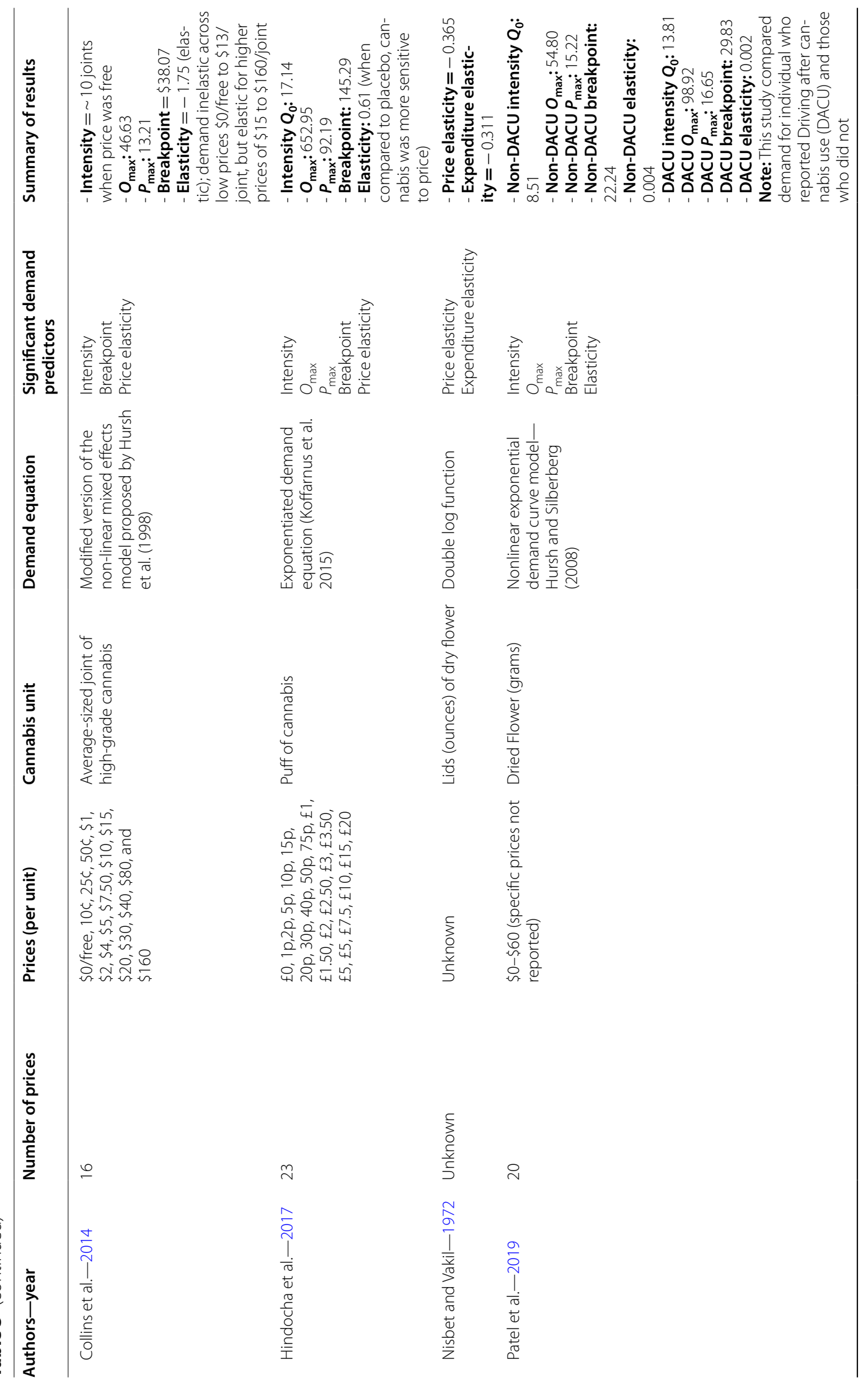


Donna et al. Journal of Cannabis Research

(2022) $4: 9$

Page 14 of 27

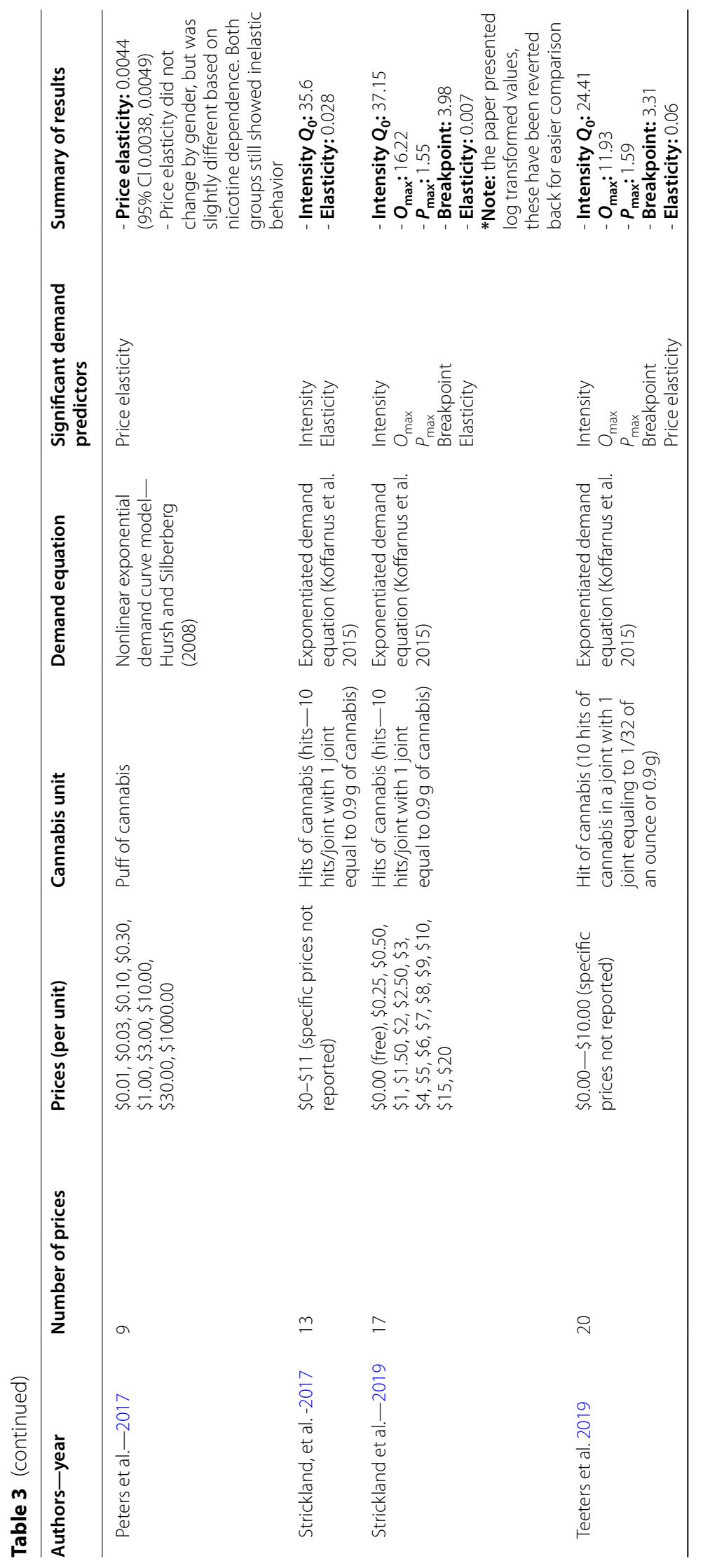




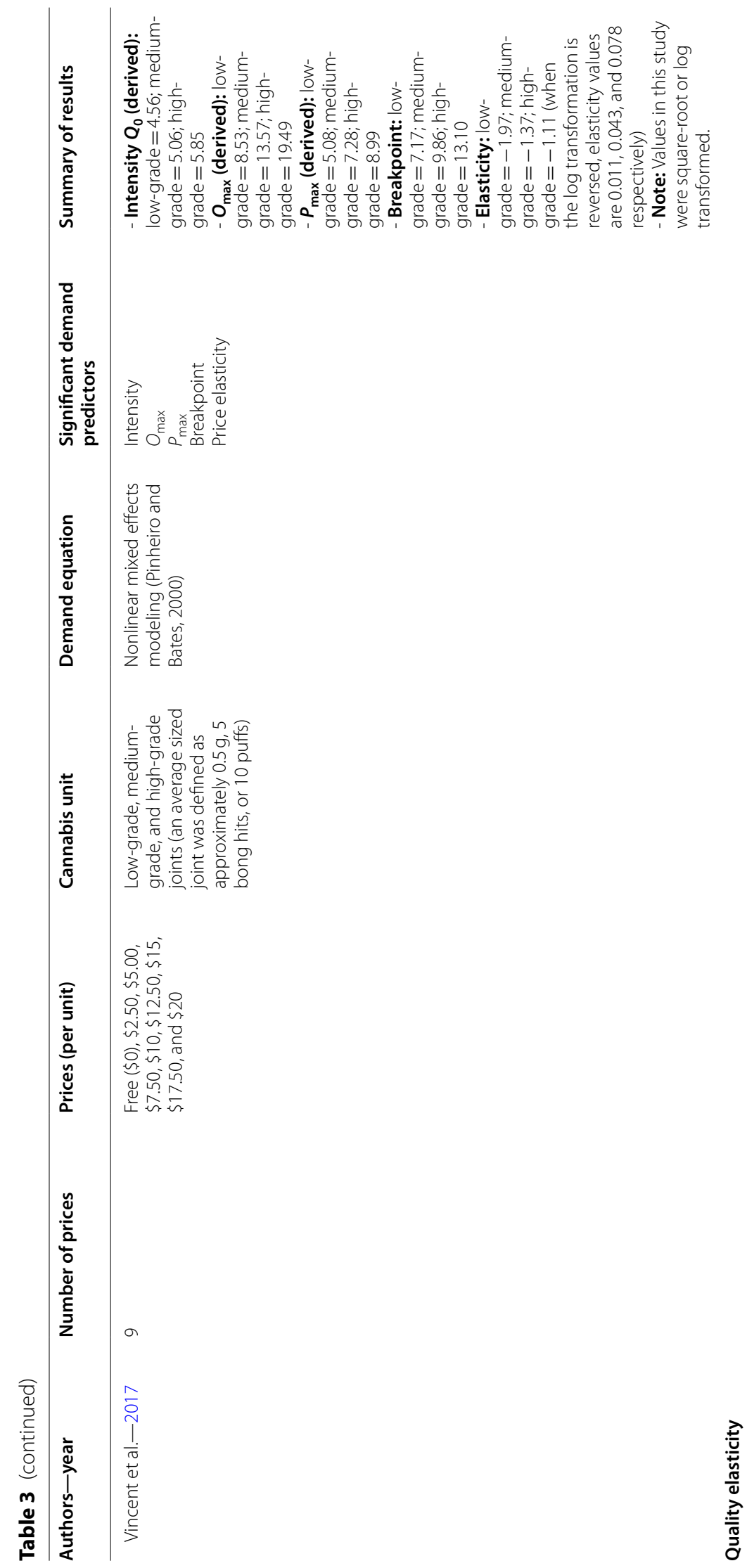




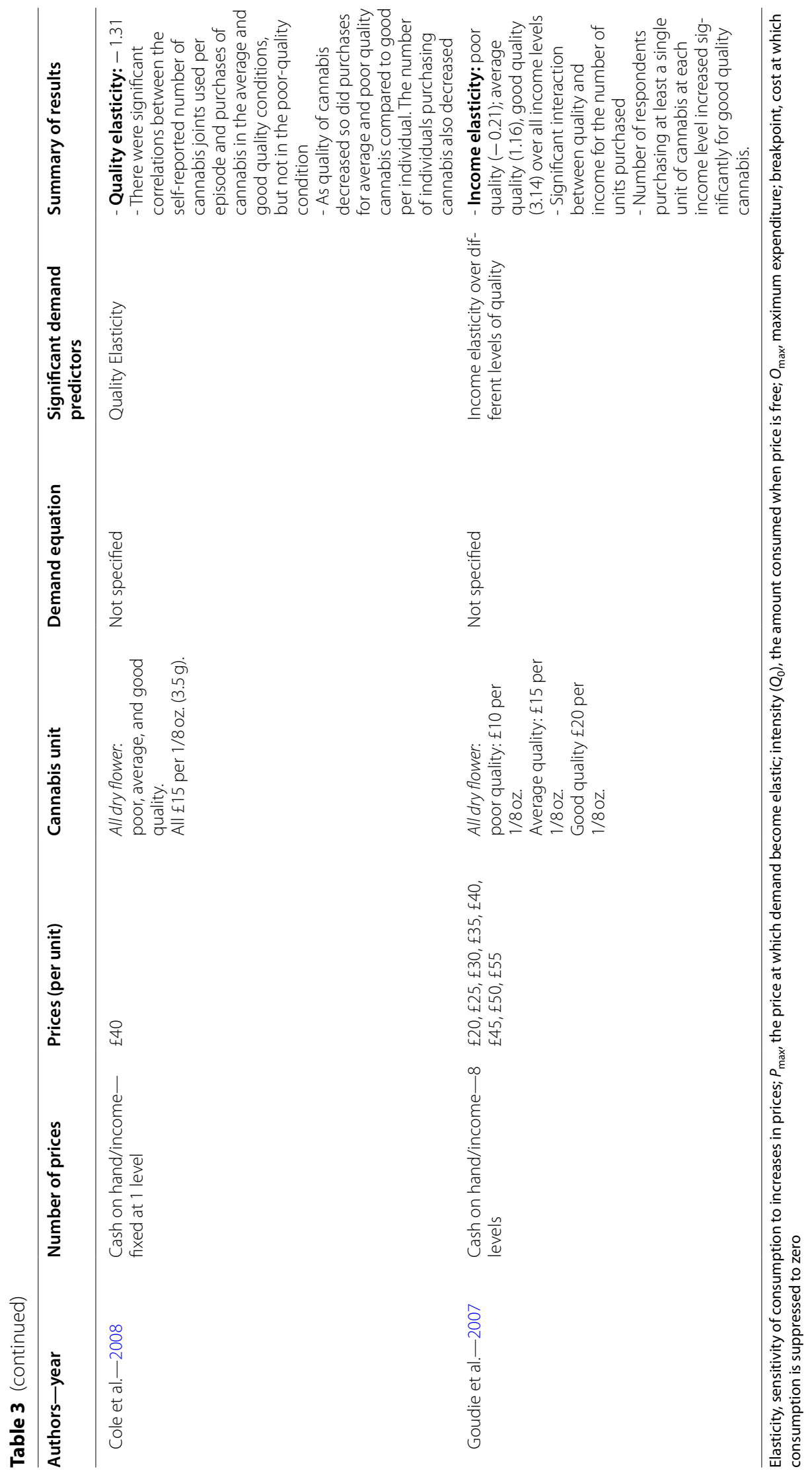




\section{Non-marijuana purchase task (non-MPT) studies}

There were fifteen non-MPT studies which examined aspects of price (Table 4), including price elasticity of demand $(n=8)$ (Ben Lakhdar et al., 2016; Davis et al., 2016; Desimone and Farrelly, 2003; Halcoussis et al., 2017; Hansen et al., 2017; Reinarman, 2009; Riley et al., 2020; Williams, 2004), quantity discount $(n=5)$ (Ben Lakhdar et al., 2016; Caulkins and Pacula, 2006; Riley et al., 2020; Smart et al., 2017; Wadsworth et al., 2019), relative importance of price $(n=1)$ (Shi et al., 2019), and price by source $(n=3)$ (Capler et al., 2017; Wadsworth et al., 2019).

With respect to price elasticity, demand was inelastic in most cases; however, some studies noted heterogeneity with respect to population and timeframe. Reinarman et al. (2009) found that the price was inelastic for experienced users and more elastic for novice users, while Williams et al. (2004) found youth to be more price sensitive than older age groups. Hansen et al. (2017) found price to be elastic in the two weeks before and after a price change as a result of a tax reform in Washington State. Finally, Riley et al. (2020) found differences in elasticity based on quality with medium and high-quality cannabis having a greater price elasticity. Davis et al. (2016) found a significant difference in the price people would pay per gram with high-quality cannabis retailing for an average of $\$ 13.77$ per gram and low-quality cannabis at an average of $\$ 5.63$ per gram, as per crowd sourced price data. Ben Lakhdar et al. (2016) was the only study that found price to be elastic consistently; however, this study only examined short term elasticity among regular consumers.

Five studies examined quantity discounts (Ben Lakhdar et al., 2016; Caulkins and Pacula, 2006; Riley et al., 2020; Smart et al., 2017; Wadsworth et al., 2019), and all studies found that price decreased with an increase in quantity purchased. Ben Lakhdar et al. (2019) found however that the degree of discount differed by geographic region, with larger cities offering cannabis at lower prices per gram.

One study explored the relative importance of price in purchase decisions. This discrete choice experiment found that price was an important factor in purchase decisions for all users. It was the most important attribute considered for non-medicinal and dual (non-medicinal and medicinal) consumers; however, price was not as important as CBD content for medicinal users (Shi et al., 2019).

Three studies looked at differences in price by source (Capler et al., 2017; Reed et al., 2020; Wadsworth et al., 2019). Wadsworth et al. (2019) found that compared to purchasing from a family member or friend, purchasing from an illicit dealer, licensed producer, and online/ mail order was associated with a higher price per gram, at a rate of $16.1 \%, 33.5 \%$, and $23.7 \%$ respectively. Capler et al. (2017) reported on satisfaction with various sources in terms of price. People were most satisfied with the price from growers, self-producers and Health Canada, somewhat satisfied with friends and dispensaries, and not satisfied with the price through street dealers. Reed et al. (2020) noted that some consumers shopped around based on new customer specials.

\section{Non-price-related factors}

Many non-price factors were explored in the included studies. These factors have been grouped into the following broad categories: $(1)$ quality $(n=11)$ (Boehnke et al., 2019; Capler et al., 2017; Chait and Burke, 1994; Cole et al., 2008; Gilbert and DiVerdi, 2018; Goudie et al., 2007; Halcoussis et al., 2017; Reinarman, 2009; Riley et al., 2020; Shi et al., 2019; Vincent et al., 2017), (2) route of administration $(n=3)$ (Aston et al., 2019; Boehnke et al., 2019; Capler et al., 2017), (3) product recommendations $(n=1)$ (Boehnke et al., 2019), (4) packaging $(n=2)$ (Goodman et al., 2019; Shi et al., 2019), and other $(n=6)$ (Table 4) (Boehnke et al., 2019; Capler et al., 2017; Reed et al., 2020; Reinarman, 2009; Shukla, 2003; Wadsworth et al., 2019).

\section{Quality}

Within the eleven studies that examined perceived cannabis quality, several different components of quality were explored. These include (1) demand elasticity based on perceived quality $(n=5)$ (Cole et al., 2008; Goudie et al., 2007; Halcoussis et al., 2017; Riley et al., 2020; Vincent et al., 2017), (2) product potency, strain $(n=4)$ (Boehnke et al., 2019; Chait and Burke, 1994; Reinarman, 2009; Shi et al., 2019), (3) aroma and visual appeal $(n=2)$ (Boehnke et al., 2019; Gilbert and DiVerdi, 2018), and quality by source $(n=1)$ (Capler et al., 2017).

Impact of quality on demand elasticity Five studies looked at the impact of perceived cannabis product quality on demand (Cole et al., 2008; Goudie et al., 2007; Halcoussis et al., 2017; Riley et al., 2020; Vincent et al., 2017). Halcoussis et al. (2017) found that low and high-quality cannabis had a positive demand elasticity compared to medium-quality when price was held constant. Somewhat conversely, Riley et al. (2020) found that medium and high-quality cannabis was purchased in greater quantity than a low-quality product when price was constant. Three studies used the MPT approach to measure different types of elasticity with respect to perceived quality. The first looked at demand elasticity over different levels of quality (Cole et al., 2008) and found demand to be elastic (elasticity $=-1.31$ ). A second study used the MPT approach but measured income elasticity over 


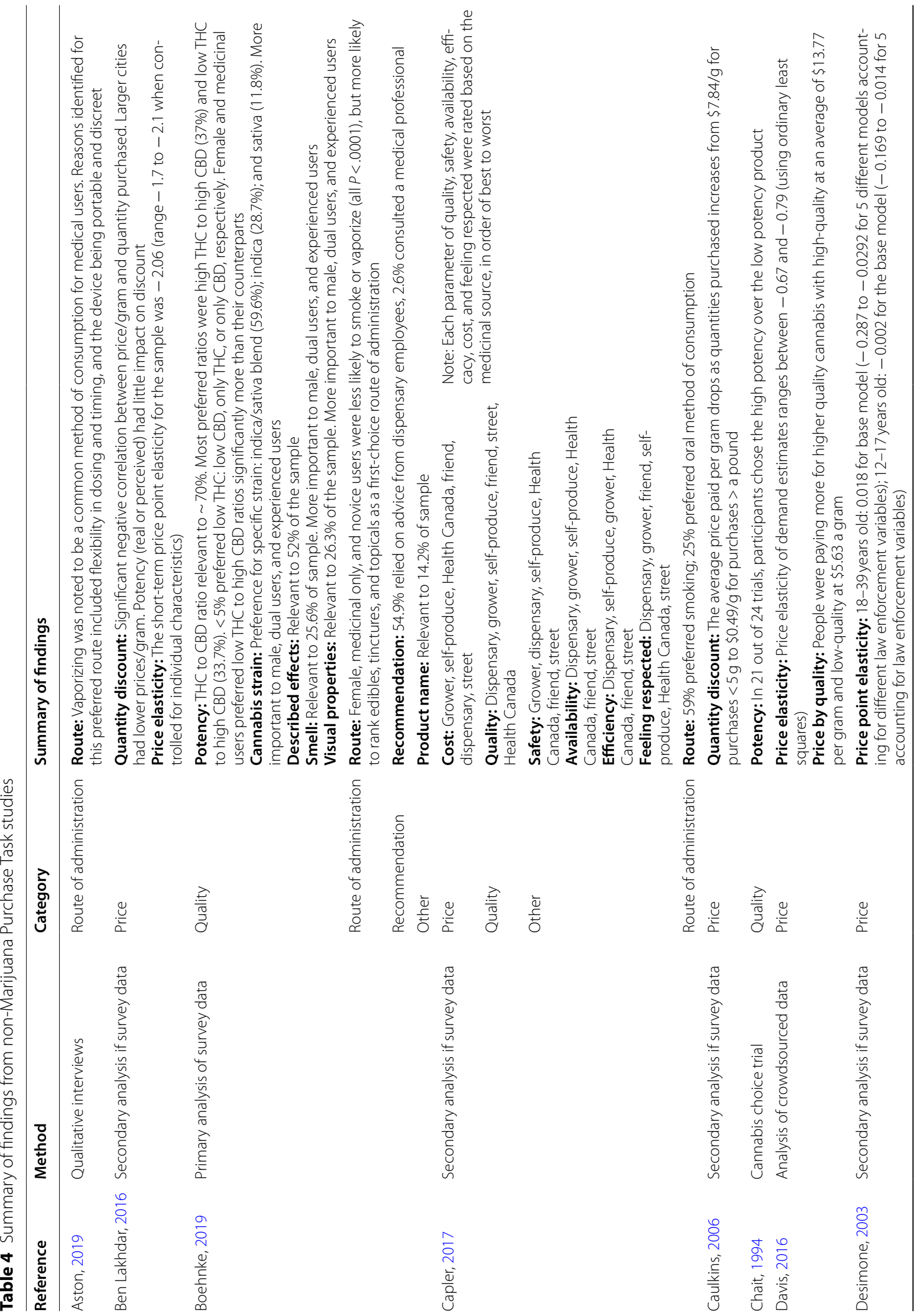




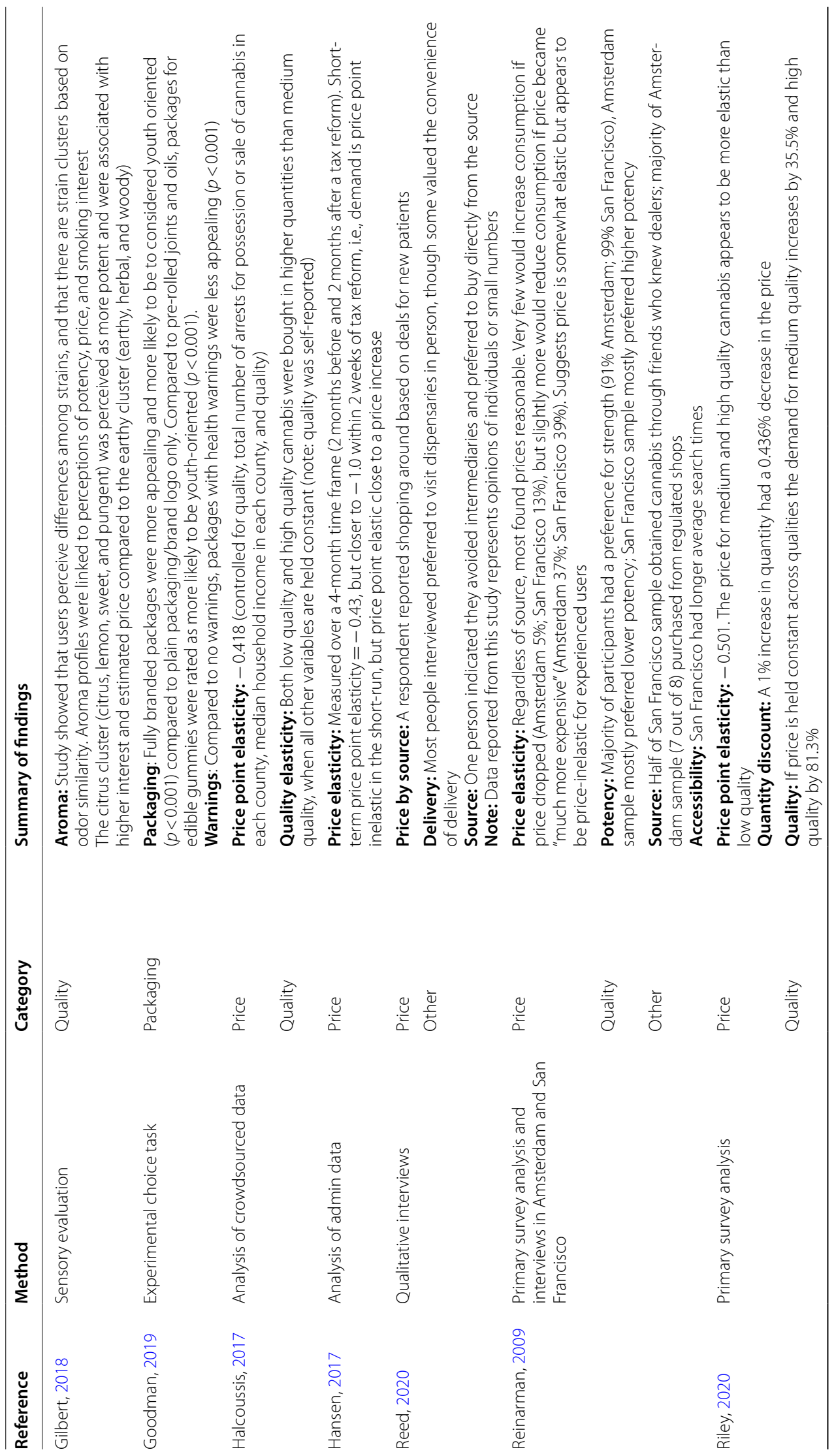




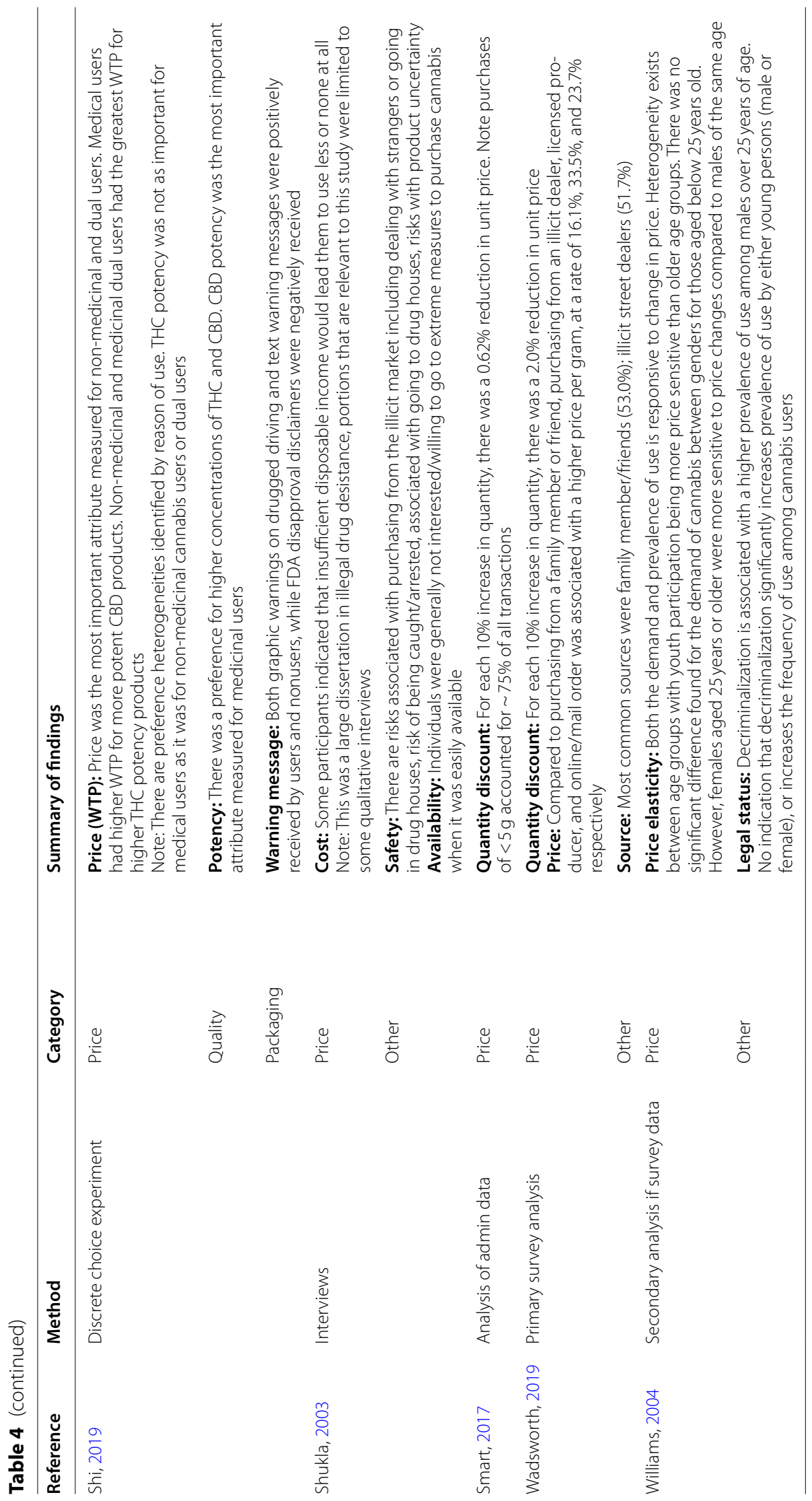


different levels of quality (Goudie et al., 2007). Demand was income inelastic for low and average quality cannabis, but income elastic for good quality cannabis. Finally, a third study measured price elasticity over different quality grades (Vincent et al., 2017); they found price elasticity to increase with increasing quality grade.

Potency and strain Overall, studies found that people generally had a preference regarding THC and CBD potency and that most preferred higher concentrations. However, there was some heterogeneity depending on reason for use, geography, and gender. Two studies found that medicinal users preferred cannabis with more CBD and less THC compared to dual users who preferred higher levels of both THC and CBD (Boehnke et al., 2019; Shi et al., 2019). Although both studies found that cannabinoid content played the biggest role in determining the cannabis product selected, dual users seemed to place more value on THC concentration, while medical users placed greater value on CBD concentration. Nonmedicinal users preferred more potent cannabis (Chait and Burke, 1994; Reinarman, 2009; Shi et al., 2019). With respect to gender, Boehnke et al. (2019) found that men preferred cannabis with both high THC and high CBD, while women preferred cannabis that had a low THC to high CBD ratio. Additionally, men were more likely consider the cannabinoid content when selecting a cannabis product.

One study comparing preferences between Amsterdam and San Francisco found that people from Amsterdam preferred mild and moderate-strength cannabis, while in San Francisco, they preferred strong and very strong cannabis (Reinarman, 2009). This study also found that approximately two thirds of people would use less cannabis than normal if they were using strong or very strong cannabis (Reinarman, 2009).

In the study by Boehnke et al. (2019), about half of the participants took into consideration the cannabis strain and described effects when deciding on what product to purchase. About two thirds preferred indica/sativa hybrid strains, about one quarter preferred indica strains, and $10 \%$ preferred sativa strains. Strain was more important to male users, dual users, and experienced users. Described effects were more important to dual and experienced users, but there was no difference between genders.

Aroma and visual appeal Gilbert and DiVerdi (2018) found that respondents were interested in smoking cannabis with citrus/sweet/lemon/pungent aromas and that these were also perceived as more expensive and potent compared to earthy/herbal/woody aromas. The price and experimentally determined level of THC of the strains, however, did not show any relationship with that of the consumers' perception. Boehnke et al. (2019) broke down their survey findings by reason for use, gender, and experienced versus novice users. They found that smell was of greater importance to people who consumed for both medicinal and non-medicinal purposes compared to using solely for medicinal reasons, medicinal users alone, males, and more experienced users.

Boehnke et al. (2019) was the only study that explored visual appeal. Overall, visual appeal was important to $26.3 \%$ of users and was more relevant to male users, dual users, and experienced users.

Quality by source Only one study rated cannabis quality by source (Capler et al., 2017). Participants were asked to rank various cannabis characteristics based on the source. Sources by best to worst quality were dispensary, grower, self-produce, friend, street, and, finally, Health Canada.

\section{Route of administration}

Two surveys (Boehnke et al., 2019; Capler et al., 2017) and a qualitative study (Aston et al. 2019) looked at preferred administration route. Smoking was the preferred route at $59 \%$; however, they found that vaporizing was the most common second choice at $29 \%$, with about one quarter preferring oral products, followed by tinctures (13.7\%), edibles (12.2\%), and topical applications (4.1\%) (Boehnke et al., 2019). Preferences differed by reason for use, gender, and experience. Medicinally, preferences were more scattered with one quarter preferring smoking, another quarter vaporization, less than one fifth tinctures, and about $15 \%$ edibles. Men ranked smoking and vaporizing as their preferred methods, while a higher proportion of women preferred topical and tinctures. Novice users preferred vaporizing (34.8\%), followed by smoking (26.1\%), tinctures (18.5\%), and edibles (14.2\%), while experienced users preferred smoking (47.2\%), followed by vaporizing (25.6\%), edibles (11.1\%), and tinctures (10.9\%).

Aston et al. (2019) explored medicinal cannabis users' preferences for vaporization in more detail. Medical consumers liked the flexibility that vaporizing allowed them for dosing and timing and also found the vaping devices to be portable and discreet.

Capler et al. (2017) compared preferences for route based on the source of cannabis. They found that preference did not differ for users who acquired cannabis through dispensaries versus those who acquired from other means, including private company under contract 
with Health Canada, self-production, other producer, friend or acquaintance, or street dealer.

\section{Product recommendations}

Another factor that influenced consumer choice was product recommendations by dispensary employees and/ or friends. Boehnke et al. (2019) found in their survey that, collectively, over half of medicinal and dual users credited dispensary employees in assisting them selecting a cannabis product, while under one quarter attributed recommendations from friends. A larger proportion of medicinal users, however, relied on recommendations from dispensary employees, and a large proportion of dual users relied on recommendations from friends. Experienced users were more likely to rely on recommendations from a friend, while novice users were more likely to rely on recommendations from a dispensary employee. There was no difference in preferred recommendation source between men and women.

\section{Packaging}

Goodman et al. (2019) determined in their survey that fully branded products were more appealing than those with either plain packaging or brand logo only. This study also found that for warning messages in general, participants ranked packages without warning messages more appealing than packages with warning messages. With respect to packaging appeal by product type, they found that edible gummies were the most appealing product, followed by pre-rolled joints, and then cannabis oil. Additionally, edible gummies and pre-rolled joints were rated to be significantly more appealing and more likely to be youth oriented when in fully branded packaging, compared to plain packaging or brand logo only packaging. However, the influence of product packaging on appeal tended to decrease with age.

Shi et al. (2019) found that cannabis consumers preferred text warning displays instead of graphic warnings in a discrete choice experiment. There was some preference heterogeneity between user types with medicinal users preferring warning displays in text, recreational non-medicinal users in graphic displays, and dual users preferred the FDA disclaimer in addition to graphic warning displays.

\section{Other}

Other attributes of choice that were explored include source (Reinarman, 2009; Wadsworth et al., 2019), product name (Boehnke et al., 2019), safety (Capler et al., 2017; Shukla, 2003), availability (Capler et al., 2017; Shukla, 2003), efficiency (Capler et al., 2017), feeling respected (Capler et al., 2017), accessibility (Reinarman,
2009), and delivery (Aston, 2019). For details on findings, refer to Table 4.

\section{Discussion}

This systematic review sought to examine attributes that influenced cannabis consumers' purchasing decisions. While price was the most researched attribute, other attributes like characteristics of quality, packaging, route of administration, and product recommendations also influenced purchase decisions. Media reports often claim that attributes such as high price, poor quality, limited supply, distance to stores, and inconvenient packaging of legal cannabis products are reasons why consumers continue to purchase from illegal sources (CBC News, 2019; Cecco, 2019; Esfandiari, 2019; Geraghty, 2019; Johnson, Glen et al., 2019; Lamers, 2019; Mazur, 2019; Tunney, 2019a; Turvill, 2020; Williams, 2019). However, as cannabis legalization is relatively recent, the number of studies which have explored these attributes is limited. In general, there is a dearth of evidence to support understanding of the role that any attributes play on cannabis consumer choice, outside of price.

The attribute of price constituted a majority of the reviewed literature. These studies were conducted mostly in populations where cannabis had not been legalized for non-medical use, while others were in populations where cannabis status was legalized, unknown, or mixed. Legalization creates a shift in the demand curve and therefore, it is important to consider this aspect when interpreting demand functions. It is also important to recognize that there is considerable heterogeneity in how the values for elasticity are derived across MPT studies. Some studies examine revealed choices by looking at transaction records, while others with examine stated choices using hypothetical scenarios. The prices and units of cannabis included varied from puffs to whole joints or grams of cannabis. Instructional vignettes and choice parameters used to describe the purchase decision varies greatly across studies which can impact demand (Aston and Meshesha, 2020). Finally, included studies used a variety of different demand equations; therefore, comparison of demand predictors cannot be compared directly to one another. The purpose of this study was not to examine the impact of price in detail. For a more in-depth interpretation of price and price elasticity measured through using MPT design, Aston et al. (2019) provides a comprehensive review.

When consumers were faced with a choice of different sources of cannabis offering the same product at different prices, people chose the product at the lower cost as shown in the study by Shi et al. (2019). In Canada, cannabis purchased from Health Canada licensed producers was associated with the greatest price per gram out of the 
examined sources, being over double the price per gram of illicit sources (Wadsworth et al., 2019). Quantity discount might also explain the large difference in price per gram between legal and illegal cannabis. It appears that the effect of quantity discount and a general lower price per gram of illegal cannabis may offer an explanation as to why the illicit market continues to thrive despite cannabis legalization.

Packaging also appeared to influence product selection, however studies that explored packaging did so through hypothetical questionnaires and focused solely on branding and warning messages (Shi et al., 2019; Wadsworth et al., 2019) and did not investigate legal cannabis's oversized and wasteful packaging as described in media reports (Lamers, 2019). Given public pressure to be more environmentally conscious, excess packaging may have the potential to influence where consumers purchase cannabis. No studies have looked at the impact of packaging on real purchase decisions.

Media reports claim that legal cannabis is of lower quality than illegal cannabis (Turvill, 2020). However, there is insufficient evidence to support this claim as quality was either insufficiently defined or not examined in the studies reviewed here. Quality could be interpreted as any combination of label accuracy, potency, presence of contaminants or pesticides, curing process, ability to give desired effect, size, visual properties, and aroma ("How to buy good weed," 2020). More research is needed to explore cannabis quality and how that is defined by consumers. One aspect of quality that perhaps does provide some insight into the strong illegal market is the higher potency of cannabis available on the illicit market (Mahamad et al., 2020). Generally speaking, medicinal users preferred high CBD content, while dual and nonmedicinal users preferred high THC content (Shi et al., 2019).

Exploring gender differences that influence purchase decisions is an important consideration given that that cannabis use was more prevalent among males than females (CCSA, 2019). There also appeared to be sexbased physiological, behavioral, and neurobiological differences in cannabinoid effects, which may play a role in product selection (Fattore and Fratta, 2010). Although many of the studies examined included male and female participants, there were only a few areas where gender preferences were highlighted. Men tended to choose products with higher potency and preferred smoking or vaping, as compared to women who chose lower potency products and preferred topicals or tinctures (Boehnke et al., 2019). Men also tended to consider strains and the smell of the product when selecting cannabis to purchase (Boehnke et al., 2019). However, it is unknown if there are gender differences when considering other attributes in product selection, such as price, quality, packaging, and product recommendations. A recent scoping review reported on how gender norms influence patterns of cannabis use (Hemsing and Greaves, 2020). Further research on gender differences when choosing cannabis products is needed.

The goal of cannabis legalization in many jurisdictions is to protect public health through safety and quality regulations (ACT Government, 2020; Spithoff et al., 2015). However, cannabis is still purchased from the illegal market (Canada, 2020; George-Cosh, 2019), so a better understanding of the attributes that people consider when purchasing products will help inform the reasons for choosing between the illegal and legal markets. This study has provided a better understanding of these attributes; however, it also highlights that there are significant gaps in our knowledge in this area. A more thorough knowledge of cannabis consumer purchasing preferences can help policy makers refine the existing policies that will protect public health and safety while meeting the needs of consumers.

\section{Limitations}

There were several limitations in this systematic review. Given cannabis legalization is relatively recent and restricted to a few countries, the literature regarding this topic is limited and the number of studies exploring each attribute is scarce, especially in a post-legalization context. Although price was the most common attributed examined, many of the studies that examined aspects of price did so using distinct methodologies and data sources that should not be considered together. In studies that captured data on purchase history through a survey, prices were often exaggerated or recalled incorrectly, whereas administrative data captured actual purchase behavior. Studies using the MPT design captured data in an experimental setting, and the effect of price on purchases were considered more objective despite being a hypothetical measure.

Outside of price, it is difficult to draw clear conclusions on the influence of other attributes on purchase decisions. Many studies focused on only one, or a small number of factors, and therefore, very little is known about the relative importance of each. There was insufficient data on many of the attributes, including aroma/ taste, described effects, product recommendations, provenance, product strain, stigma, product safety, and personal safety, thus limiting the ability to make any estimate on the degree to which these attributes influence choice. Heterogeneity among the study methods and samples also makes it difficult to generalize many of the findings. Several studies had very narrow inclusion criteria and were therefore only representative of that subset of the 
population, or the sample size was very small. For several of the studies that met our inclusion criteria, choice attributes were often not the primary outcome examined and therefore lacked detail regarding those choice attributes.

Preferences for cannabis products likely differ across consumers based on frequency of use. There were no studies that broke down findings based on consumer use frequency. Qualitative methods were used in only three studies, which limits the depth of understanding especially around non-price attributes. There was also a lack of youth perspectives when making purchase decisions and only a few studies identified gender influences on product choice.

Finally, the literature to date has mainly focused on choices for dried flower cannabis. However, attributes of purchase choices likely differ across product types. For example, visual appeal may be less important for a cannabis beverage purchase compared to dried flower. There is currently no research evidence that helps us to appreciate heterogeneity in choice behavior by product type or route of administration.

While this study is a thorough review of the available literature on consumer preferences for cannabis products, the limitations noted above prevent us from drawing any specific conclusions based on the data.

\section{Future research}

Future research is needed to develop a more thorough understanding of the non-price related attributes that people use when choosing cannabis products as well as the relationship between these various attributes. Factors cited by the media, such as distance to licensed stores, cannabis supply, product moisture, and bulky and wasteful packaging, lack evidence and remains to be studied. Quality of the product is poorly studied and has varied meanings, so research is needed to determine what quality means to people and how it influences purchase decisions. With the increasing use of cannabis use among youth (Canada, 2019), it will be important to explore the factors for their choices. Finally, an appreciation for potential heterogeneity among choices based on consumer characteristics (e.g., gender, reason for cannabis use, frequency of use) as well as type of cannabis product (e.g., dried flower, oil, edible) is needed.

\section{Conclusions}

This systematic review presents a summary of findings from current literature regarding attributes of choice when consumers purchase cannabis products. The majority of studies focused on price-related attributes whereas three studies contributed a large proportion of findings for non-price attributes. Demand is generally inelastic with respect to price, but the degree of elasticity varies by age, gender, and experience with cannabis. Preferences were greater for products with higher potency of either THC or CBD, but this also changed based on reason for use and gender. There is insufficient evidence to understand the true impact of other attributes on the choices of cannabis consumers and the relationship between attributes. Going forward, additional research will support a more thorough understanding of these attributes, which can offer a better explanation of consumers' thoughts and opinions. This information will be useful for helping policy makers refine the existing policies to better support public health and safety and meet consumer needs. It can also offer insight for countries looking to legalize cannabis for either medicinal or non-medicinal use.

\section{Abbreviations}

CBD: Cannabidiol; DACU: Driving after cannabis use; MMAT: Mixed Methods Appraisal Tool; MPT: Marijuana Purchase Task; THC: Tetrahydrocannabinol.

\section{Supplementary Information}

The online version contains supplementary material available at https://doi. org/10.1186/s42238-022-00117-0.

Additional file 1.

\section{Acknowledgements \\ The authors would like to acknowledge Alison Farrell for her peer review of the search strategy used in this systematic review.}

\section{Authors' contributions}

$J D, L B$, and MN are principal investigators of and designed Partnerships for Cannabis Policy Evaluation, Newfoundland and Labrador Study. MS prepared the literature search strategy. JD and OS screened papers, extracted and analyzed data, and prepared the manuscript. LB and MN provided critical feedback and edits on the manuscript. All authors have read and approved the final manuscript.

\section{Funding}

This study has been supported through a grant jointly given by the Canadian Centre for Substance use and Addiction and the Canadian Institutes for Health Research (Grant Number: 201910CPV). Neither organization played a role in conducting this research.

Availability of data and materials

Complete search strategy and detailed study tables are included in the supplementary appendix.

\section{Declarations}

Ethics approval and consent to participate

Not applicable.

Consent for publication

Not applicable.

Competing interests

The authors declare that they have no competing interests. 


\section{Author details}

'School of Pharmacy, Memorial University of Newfoundland and Labrador, St. John's, Canada. ${ }^{2}$ Faculty of Medicine, Memorial University of Newfoundland and Labrador, St. John's, Canada.

Received: 25 January 2021 Accepted: 3 January 2022 Published online: 01 February 2022

\section{References}

ACT Government, 2020. ACT - Cannabis [WWW document]. ACT Gov. URL https://www.act.gov.au/cannabis/home (accessed 6.22.20).

Ahearn, V., 2018. \#Cannabis: Canada keeping black market alive, Tommy Chong says [WWW document]. Montr Gaz URL https://montrealgazette. com/life/cannabis-canada-keeping-black-market-alive-tommy-chongsays (accessed 6.23.20).

Amlung M, MacKillop J. Availability of legalized cannabis reduces demand for illegal cannabis among Canadian cannabis users: evidence from a behavioural economic substitution paradigm. Can J Public Health Rev Can Sante Publique. 2019;110:216-21 https://doi.org/10.17269/ s41997-018-0160-4.

Amlung M, Reed DD, Morris V, Aston ER, Metrik J, MacKillop J. Price elasticity of illegal versus legal cannabis: a behavioral economic substitutability analysis. Addiction. 2019;114:112-8. https://doi.org/10.1111/add.14437.

Areesantichai C, Perngparn U, Pilley C. Current cannabis-related situation in the Asia-Pacific region. Curr Opin Psychiatry. 2020;33:352-9. https://doi. org/10.1097/YCO.0000000000000616.

Aston ER, Meshesha LZ. Assessing cannabis demand: a comprehensive review of the marijuana purchase task. Neurother J Am Soc Exp Neurother. 2020;17:87-99. https://doi.org/10.1007/s13311-019-00819-z.

Aston ER, Metrik J, Amlung M, Kahler CW, MacKillop J. Interrelationships between marijuana demand and discounting of delayed rewards: convergence in behavioral economic methods. Drug Alcohol Depend. 2016:169:141-7. https://doi.org/10.1016/j.drugalcdep.2016.10.014.

Aston ER, Metrik J, MacKillop J. Further validation of a marijuana purchase task. Drug Alcohol Depend. 2015;152:32-8. https://doi.org/10.1016/j.druga Icdep.2015.04.025.

Aston ER, Scott B, Farris SG. A qualitative analysis of cannabis vaporization among medical users. Exp. Clin. Psychopharmacol. Therapeutic and Abuse-Related Effects of Cannabis and Cannabinoids. 2019;27:301-8. https://doi.org/10.1037/pha0000279.

Bahji A, Stephenson C. International perspectives on the implications of cannabis legalization: a systematic review \& thematic analysis. Int J Environ Res Public Health. 2019;16. https://doi.org/10.3390/ijerph16173095.

BBC News. South Africa legalises cannabis use: BBC News; 2018.

Ben Lakhdar CG, Vaillant N, Wolff FC. Price elasticity of demand for cannabis: does potency matter? Addict Res Theory. 2016;24:300-12. https://doi. org/10.3109/16066359.2016.1139699.

Boehnke KF, Scott JR, Litinas E, Sisley S, Clauw DJ, Goesling J, et al. Cannabis use preferences and decision-making among a cross-sectional cohort of medical cannabis patients with chronic pain. J Pain. 2019;20:1362-72. https://doi.org/10.1016/j.jpain.2019.05.009.

Canada H. Canadian Cannabis survey 2019 - summary [WWW document]. aem. 2019; https://www.canada.ca/en/health-canada/services/publicatio ns/drugs-health-products/canadian-cannabis-survey-2019-summary. html (accessed 8.24.20).

Canada, H., 2020. Canadian Cannabis survey 2020: summary [WWW document]. Aem. URL https://www.canada.ca/en/health-canada/services/ drugs-medication/cannabis/research-data/canadian-cannabis-survey2020-summary.html (accessed 1.18.21).

Capler R, Walsh Z, Crosby K, Belle-Isle L, Holtzman S, Lucas P, et al. Are dispensaries indispensable? Patient experiences of access to cannabis from medical cannabis dispensaries in Canada. Int J Drug Policy. 2017:47:1-8. https://doi.org/10.1016/j.drugpo.2017.05.046.

Caulkins JP, Pacula RL. Marijuana markets: inferences from reports by the household population. J Drug Issues. 2006;36:173-200. https://doi.org/ $10.1177 / 002204260603600108$.

CBC News. High demand for legal cannabis good for government - but low supply still punishing retailers | CBC News [WWW document]. CBC. 2019; https://www.cbc.ca/news/canada/newfoundland-labrador/tom-osbor ne-cannabis-supply-1.5044658 (accessed 6.23.20).

CCSA, 2019. Clearing the smoke on cannabis: highlights — an update.

Cecco L. Canada's legal weed struggles to light up as smokers stick to black market. The Guardian. 2019.

Chait LD, Burke KA. Preference for high- versus low-potency marijuana. Pharmacol Biochem Behav. 1994;49:643-7. https://doi.org/10.1016/00913057(94)90082-5.

Cole JC, Goudie AJ, Field M, Loverseed A-C, Charlton S, Sumnall HR. The effects of perceived quality on the behavioural economics of alcohol, amphetamine, cannabis, cocaine, and ecstasy purchases. Drug Alcohol Depend. 2008;94:183-90. https://doi.org/10.1016/j.drugalcdep.2007.11.014.

Collins RL, Vincent PC, Yu J, Liu L, Epstein LH. A behavioral economic approach to assessing demand for marijuana. Exp Clin Psychopharmacol. 2014;22:211-21. https://doi.org/10.1037/a0035318.

Cooke A, Smith D, Booth A. Beyond PICO: the SPIDER tool for qualitative evidence synthesis. Qual Health Res. 2012;22:1435-43. https://doi.org/10. $1177 / 1049732312452938$

Davis AJ, Geisler KR, Nichols MW. The price elasticity of marijuana demand: evidence from crowd-sourced transaction data. Empir Econ Heidelb. 2016;50:1171-92 http://dx.doi.org.qe2a-proxy.mun.ca/10.1007/ s00181-015-0992-1.

Deschamps, T., 2020. Illegal cannabis prices fall as legal market expands national | globalnews.Ca [WWW document]. Glob News URL https:// globalnews.ca/news/6456276/illegal-cannabis-prices-fall/ (accessed 6.23.20).

Desimone J, Farrelly MC. Price and enforcement effects on cocaine and marijuana demand. Econ Inq Huntingt Beach. 2003;41:98-115.

Esfandiari S. Canadians still buy weed from black market 1 year after legalization - business insider [WWW document]. Insid: Bus; 2019. https://WwW. businessinsider.com/canada-weed-black-market-boom-despite-legalizati on-2019-10 (accessed 6.23.20)

Fahmy G. Demand for illegal cannabis still high, 1 year after legalization | CBC News [WWW document]. CBC. 2019; https://www.cbc.ca/news/canada/ new-brunswick/cannabis-one-year-illegal-sales-nb-1.5323130 (accessed 6.23.20).

Fattore L, Fratta W. How important are sex differences in cannabinoid action?: sex differences in cannabinoid action. Br J Pharmacol. 2010;160:544-8. https://doi.org/10.1111/j.1476-5381.2010.00776.x.

George-Cosh D. Pot sector's "teething pains" to lower sales by $30 \%$ : scotia article [WWW document]. BNN. 2019; https://www.bnnbloomberg.ca/ canadian-pot-sector-s-teething-pains-to-lower-sales-by-30-scotiabank-1. 1210088 (accessed 8.24.20).

Geraghty J. Canada's weed industry gets a tough lesson in supply and demand. Rev: Natl; 2019. https://www.nationalreview.com/corner/ canadas-weed-industry-gets-a-tough-lesson-in-supply-and-demand/ (accessed 6.23.20)

Gilbert AN, DiVerdi JA. Consumer perceptions of strain differences in Cannabis aroma. PLoS One. 2018;13:e0192247. https://doi.org/10.1371/journal. pone.0192247.

Gilroy SP, Kaplan BA, Reed DD. Interpretation(s) of elasticity in operant demand. J Exp Anal Behav. 2020;114:106-15. https://doi.org/10.1002/ jeab.610.

Goodman S, Leos-Toro C, Hammond D. The impact of plain packaging and health warnings on consumer appeal of cannabis products. Drug Alcohol Depend. 2019;205. https://doi.org/10.1016/j.drugalcdep.2019.107633.

Goudie AJ, Sumnall HR, Field M, Clayton H, Cole JC. The effects of price and perceived quality on the behavioural economics of alcohol, amphetamine, cannabis, cocaine, and ecstasy purchases. Drug Alcohol Depend. 2007;89:107-15. https://doi.org/10.1016/j.drugalcdep.2006.11.021.

Guthrie, S., 2018. Ministry of Internal Affairs Releases Planned Marijuana use Regulations [WWW document]. Ga. Today Web. URL http://georgiatoday. ge/news/12155/Ministry-of-Internal-Affairs-Releases-Planned-MarijuanaUse-Regulations (accessed 6.22.20).

Halcoussis D, Lowenberg AD, Roof Z. Estimating the price elasticity of demand for cannabis: a geographical and crowdsourced approach. Rev Métod Cuantitativos Para Econ Empresa Seville. 2017;23:119-36.

Hanford, M., n.d. Recreational cannabis legalisation in Europe - countries to watch. Volteface. URL https://volteface.me/feature/recreational-cannabislegalisation-europe-countries-watch/ (accessed 6.22.20). 
Hansen B, Miller K, Weber C. The taxation of recreational marijuana: evidence from Washington State. 2017:23632 https://doi.org/10.3386/ w23632.

Hemsing N, Greaves L. Gender norms, roles and relations and cannabis-use patterns: a scoping review. Int J Environ Res Public Health. 2020;17. https://doi.org/10.3390/ijerph17030947.

Hindocha C, Lawn W, Freeman TP, Curran HV. Individual and combined effects of cannabis and tobacco on drug reward processing in nondependent users. Psychopharmacology. 2017;234:3153-63. https://doi. org/10.1007/s00213-017-4698-2.

Hong QN, Gonzalez-Reyes A, Pluye P. Improving the usefulness of a tool for appraising the quality of qualitative, quantitative and mixed methods studies, the mixed methods appraisal tool (MMAT). J Eval Clin Pract. 2018;24:459-67. https://doi.org/10.1111/jep.12884.

How to buy good weed: Finding quality in cannabis flower, 2020. . Leafly. URL https://www.leafly.ca/news/cannabis-101/how-to-buy-goodweed (accessed 11.9.20).

Israel S. Dry pot: what are Canada's licensed producers doing about it? Winn: Free Press; 2019.

Johnson, Glen, Thompson, E., Gillies, R., 2019. Frustration and pride in Canada after a year of legal pot [WWW document]. AP NEWS. URL https:// apnews.com/f9fc0e821e464e4d9ebd5d1dc1277912 (accessed 6.23.20).

Lamers M. Canada has a cannabis packaging problem: here's what businesses are doing about it [WWW document]. Dly: Marijuana Bus; 2019. https://mjbizdaily.com/how-canadian-cannabis-companies-are-handl Ing-packaging-problems/ (accessed 6.23.20)

Mahamad S, Wadsworth E, Rynard V, Goodman S, Hammond D. Availability, retail price and potency of legal and illegal cannabis in Canada after recreational cannabis legalisation. Drug Alcohol Rev. 2020;39:337-46. https://doi.org/10.1111/dar.13069.

Mazur A. Canada's cannabis supply issues are real, despite feds' denial, says business professor [WWW document]. News: Glob; 2019. https:// globalnews.ca/news/5463653/canadas-cannabis-supply-feds-denial/ (accessed 6.23.20)

McCabe M. Facing closure, independent shop says no money in legal cannabis | CBC News [WWW document]. CBC. 2019; https://www.cbc.ca/ news/canada/newfoundland-labrador/independent-cannabis-retai ler-struggling-1.5248383 (accessed 6.23.20).

Moher D, Liberati A, Tetzlaff J, Altman DG, PRISMA Group. Preferred reporting items for systematic reviews and meta-analyses: the PRISMA statement. PLoS Med. 2009;6:e1000097. https://doi.org/10.1371/journ al.pmed.1000097.

National Academies of Sciences, E., Division, H. and M., Practice, B. on P.H. and P.H., Agenda, C. on the H.E. of M.A.E.R. and R. Cannabis: prevalence of use, regulation. In: And current policy landscape, the health effects of cannabis and cannabinoids: the current state of evidence and recommendations for research: National Academies Press (US); 2017.

National Institute of Health, 2015. Prevalence of marijuana use among U.S. adults doubles over past decade [WWW Document]. Natl. Inst. Health NIH. URL https://www.nih.gov/news-events/news-releases/preva lence-marijuana-use-among-us-adults-doubles-over-past-decade (accessed 11.6.20).

Nisbet CT, Vakil F. Some estimates of price and expenditure elasticities of demand for marijuana among U.c.l.a. students. Rev Econ Stat. 1972;54:473. https://doi.org/10.2307/1924578.

Patel $\mathrm{H}$, Amlung M. Elevated cannabis demand is associated with driving after cannabis use in a crowd-sourced sample of adults. Exp Clin Psychopharmacol. 2019;27:109-14. https://doi.org/10.1037/pha0000240.

Peacock A, Leung J, Larney S, Colledge S, Hickman M, Rehm J, et al. Global statistics on alcohol, tobacco and illicit drug use: 2017 status report. Addiction. 2018;113:1905-26. https://doi.org/10.1111/add.14234.

Peters EN, Rosenberry ZR, Schauer GL, O'Grady KE, Johnson PS. Marijuana and tobacco cigarettes: estimating their behavioral economic relationship using purchasing tasks. Exp Clin Psychopharmacol. 2017;25:20815. https://doi.org/10.1037/pha0000122.

Reed M, Kioumarsi A, Ataiants J, Fedorova EV, Iverson E, Wong CF, et al. Marijuana sources in a medical marijuana environment: dynamics in access and use among a cohort of young adults in Los Angeles. California Drugs Abingdon Engl. 2020;27:69-78. https://doi.org/10.1080/09687 637.2018 .1557595 .
Reinarman C. Cannabis policies and user practices: market separation, price, potency, and accessibility in Amsterdam and San Francisco. Int. J. Drug Policy. 2009;20:28-37. https://doi.org/10.1016/j.drugpo.2007.11.003.

Riley S, Vellios N, van Walbeek C. An economic analysis of the demand for cannabis: some results from South Africa. Drugs Educ Prev Policy. 2020;27:123-30. https://doi.org/10.1080/09687637.2019.1581139.

Shackford S. The marijuana black market will keep its throne in California, thanks to tax increases. Reason. 2019; https://reason.com/2019/11/25/ the-marijuana-black-market-will-keep-its-throne-in-california-thanks-totax-increases/ (accessed 6.23.20).

Shi Y, Cao Y, Shang C, Pacula RL. The impacts of potency, warning messages, and price on preferences for Cannabis flower products. Int. J. Drug Policy. 2019;74:1-10. https://doi.org/10.1016/j.drugpo.2019.07.037.

Shukla, R.K., 2003. A rational choice analysis of decision-making and desistance from marijuana use (Ph.D.). Rutgers the State University of new Jersey Newark, United States -- New Jersey.

Smart R, Caulkins JP, Kilmer B, Davenport S, Midgette G. Variation in cannabis potency and prices in a newly legal market: evidence from 30 million cannabis sales in Washington state: legal cannabis potency and price variation. Addiction. 2017;112:2167-77. https://doi.org/10.1111/add. 13886.

Smith P. Marijuana reform advances around the world [WWW document]. Asia Times. 2020; https://asiatimes.com/2020/01/marijuana-reform-advancesaround-the-world/ (accessed 6.22.20).

Solutions DG. Map of marijuana legality by state [WWW document]. Solut: DISA Glob; 2019. https://disa.com/map-of-marijuana-legality-by-state (accessed 1.22.21)

Spithoff S, Emerson B, Spithoff A. Cannabis legalization: adhering to public health best practice. CMAJ Can Med Assoc J. 2015;187:1211-6. https:// doi.org/10.1503/cmaj.150657.

Statistics Canada, 2020. StatsCannabis data availability: crowdsourced cannabis prices, fourth quarter 2019 [WWW Document]. URL https://www150. statcan.gc.ca/n1/daily-quotidien/200123/dq200123c-eng.htm (accessed 7.7.20).

Strickland JC, Lile JA, Stoops WW. Unique prediction of cannabis use severity and behaviors by delay discounting and behavioral economic demand. Behav Process. 2017;140:33-40. https://doi.org/10.1016/j.beproc.2017. 03.017.

Strickland JC, Lile JA, Stoops WW. Evaluating non-medical prescription opioid demand using commodity purchase tasks: test-retest reliability and incremental validity. Psychopharmacology. 2019;236:2641-52. https://doi. org/10.1007/s00213-019-05234-y.

Teeters J, Meshesha L, Dennhardt A, Murphy J. Elevated demand and proportionate substance-related reinforcement are associated with driving after cannabis use. Can J Addict. 2019;10:42-50. https://doi.org/10.1097/CXA. 0000000000000062.

The Canadian Press, 2020. Affordable legal cannabis should be priority as illegal pot prices drop, experts say | CBC News [WWW document]. CBC. URL https://www.cbc.ca/news/business/cannabis-price-gap-illegal-legal-1. 5438899 (accessed 6.23.20)

Torrance GW, Boyle MH, Horwood SP. Application of multi-attribute utility theory to measure social preferences for health states. Oper Res. 1982;30:1043-69. https://doi.org/10.1287/opre.30.6.1043.

Tunney C. "Vibrant" black market persists as legal pot marks its first full year in Canada| CBC News [WWW document]. CBC. 2019a; https://www.cbc. ca/news/politics/marijuana-one-year-black-market-1.5320552 (accessed 6.23.20).

Tunney C. "Vibrant" black market persists as legal pot marks its first full year in Canada [WWW document]. CBC. 2019b; https://www.cbc.ca/news/polit ics/marijuana-one-year-black-market-1.5320552 (accessed 6.23.20).

Turvill W. "The legal stuff is garbage": why Canada's cannabis black market keeps thriving. The Guardian. 2020.

United Nations Office on Drugs and Crime. World Drug Report. 2019:2019.

Vincent PC, Collins RL, Liu L, Yu J, De Leo JA, Earleywine M. The effects of perceived quality on behavioral economic demand for marijuana: a webbased experiment. Drug Alcohol Depend. 2017;170:174-80. https://doi. org/10.1016/j.drugalcdep.2016.11.013.

Wadsworth E, Driezen P, Goodman S, Hammond D. Differences in self-reported cannabis prices across purchase source and quantity purchased among Canadians. Addict Res Theory. 2019;0:1-10. https://doi.org/10.1080/ 16066359.2019.1689961. 
Wadsworth E, Driezen P, Hammond D. Retail availability and legal purchases of dried flower in Canada post-legalization. Drug Alcohol Depend. 2021;225:108794. https://doi.org/10.1016/j.drugalcdep.2021.108794.

Williams J. The effects of price and policy on marijuana use: what can be learned from the Australian experience? Health Econ. 2004;13:123-37. https://doi.org/10.1002/hec.796.

Williams S. 5 reasons the marijuana black market won't go away [WWW document]. Motley Fool. 2019; https://www.fool.com/investing/2019/10/ 19/5-reasons-the-marijuana-black-market-wont-go-away.aspx (accessed 6.23.20).

\section{Publisher's Note}

Springer Nature remains neutral with regard to jurisdictional claims in published maps and institutional affiliations.

- fast, convenient online submission

- thorough peer review by experienced researchers in your field

- rapid publication on acceptance

- support for research data, including large and complex data types

- gold Open Access which fosters wider collaboration and increased citations

- maximum visibility for your research: over $100 \mathrm{M}$ website views per year

At BMC, research is always in progress.

Learn more biomedcentral.com/submissions 